\title{
Article \\ Enhancement of Temperature Fluorescence Brightness of Zn@Si Core-Shell Quantum Dots Produced via a Unified Strategy
}

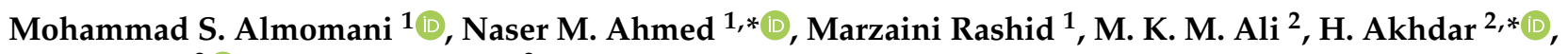 \\ O. Aldaghri ${ }^{2}(1)$ and K. H. Ibnaouf ${ }^{2}$ \\ 1 School of Physics, Universiti Sains Malaysia, Minden 11800, Penang, Malaysia; \\ Mohammadmomani36@yahoo.com (M.S.A.); marzaini@usm.my (M.R.) \\ 2 Department of Physics, College of Science, Imam Mohammad Ibn Saud Islamic University (IMSIU), \\ Riyadh 11623, Saudi Arabia; hamofarog@yahoo.com (M.K.M.A.); odaghri@gmail.com (O.A.); \\ kheo90@gmail.com (K.H.I.) \\ * Correspondence: nas_tiji@yahoo.com (N.M.A.); hfAkdar@imamu.edu.sa (H.A.)
}

check for updates

Citation: Almomani, M.S.; Ahmed, N.M.; Rashid, M.; Ali, M.K.M.; Akhdar, H.; Aldaghri, O.; Ibnaouf, K.H. Enhancement of Temperature Fluorescence Brightness of Zn@Si Core-Shell Quantum Dots Produced via a Unified Strategy. Nanomaterials 2021, 11, 3158. https://doi.org/ 10.3390/nano11113158

Academic Editor: Stefano Bellucci

Received: 6 October 2021

Accepted: 7 November 2021

Published: 22 November 2021

Publisher's Note: MDPI stays neutral with regard to jurisdictional claims in published maps and institutional affiliations.

Copyright: (c) 2021 by the authors. Licensee MDPI, Basel, Switzerland. This article is an open access article distributed under the terms and conditions of the Creative Commons Attribution (CC BY) license (https:/ / creativecommons.org/licenses/by/ $4.0 /)$.

\begin{abstract}
Despite many dedicated efforts, the fabrication of high-quality ZnO-incorporated Zinc@Silicon (Zn@Si) core-shell quantum dots (ZnSiQDs) with customized properties remains challenging. In this study, we report a new record for the brightness enhancement of ZnSiQDs prepared via a unified top-down and bottom-up strategy. The top-down approach was used to produce ZnSiQDs with uniform sizes and shapes, followed by the bottom-up method for their re-growth. The influence of various $\mathrm{NH}_{4} \mathrm{OH}$ contents (15 to $25 \mu \mathrm{L}$ ) on the morphology and optical characteristics of ZnSiQDs was investigated. The ZnSiQDs were obtained from the electrochemically etched porous Si (PSi) with Zn inclusion ( $\mathrm{ZnPSi}$ ), followed by the electropolishing and sonication in acetone. EFTEM micrographs of the samples prepared without and with $\mathrm{NH}_{4} \mathrm{OH}$ revealed the existence of spherical $\mathrm{ZnSiQDs}$ with a mean diameter of 1.22 to $7.4 \mathrm{~nm}$, respectively. The emission spectra of the ZnSiQDs (excited by $365 \mathrm{~nm}$ ) exhibited bright blue, green, orange-yellow, and red luminescence, indicating the uniform morphology related to the strong quantum confinement ZnSiQDs. In addition, the absorption and emission of the $\mathrm{ZnSiQDs}$ prepared with $\mathrm{NH}_{4} \mathrm{OH}$ were enhanced by $198.8 \%$ and $132.6 \%$, respectively. The bandgap of the $\mathrm{ZnSiQDs}$ conditioned without and with $\mathrm{NH}_{4} \mathrm{OH}$ was approximately 3.6 and $2.3 \mathrm{eV}$, respectively.
\end{abstract}

Keywords: ZnSiQDs; electrochemical etching; photoluminescence; quantum confinement; core-shell

\section{Introduction}

Inorganic semiconducting colloidal nanoparticles with uniform morphology and narrow size distribution have been widely investigated owing to their fundamental scientific importance and diverse practical applications [1]. Amongst all the recently studied semiconductor nanostructures, the colloidal Si quantum dots (SiQDs) became increasingly attractive due to their non-toxicity, abundance, and tunable bandgap energies [2]. On top of that, SiQDs can be used for a wide range of applications, such as optoelectronics, solar cells, biomedical devices, and light-emitting diodes (LEDs) [2]. Generally, both chemical and physical methods are used to synthesize SiQDs. Physical methods (bottom-up and top-down approaches) include (1) plasma synthesis: the diameter of these particles is between 2 and $8 \mathrm{~nm}$, and the emission covered all visible spectrum, but this method needs low pressure or high temperature, thereby increasing the cost of equipment and fabrications; (2) laser ablation: the advantage of this method is the clean technique, and the average particle size is between 20 and $500 \mathrm{~nm}$; to prepare a small size $(2-3 \mathrm{~nm})$ the process must be carried under low pressure, hence increasing the economic burden. The top-down chemical approach includes (3) electrochemical etching. It is the most famous method to synthesize SiQDs due to the user-friendly equipment used and facile preparation, but the size and shape of SiQDs cannot be controlled. The bottom-up approach involves (4) the 
reduction of the Si halides and Zintl phase oxidation. The size of SiQDs prepared by this method is between $5 \mathrm{~nm}$ and $3 \mu \mathrm{m}$ and requires high temperature and low pressure. One of the significant benefits of porous silicon (PSi) is its ease of production. PSi is primarily synthesized by electrochemical dissolution of Si pieces in a hydrofluoric acid solution. PSi can be created by electrochemical etching or anodization in a hydrofluoric solution. In terms of equipment and chemicals utilized, the electrochemical-etching process is a straightforward and cost-effective experimental setup [3,4]. The electrochemical-etching process is preferred to produce Si nanoparticles. In this procedure, the Si wafer (acts as a cathode) is immersed in an electrolyte made of an HF-ethanol solution, wherein the platinum (Pt) or graphite rod acts as an anode [5]. In the past, the electrochemical-etching technique has widely been used to produce colloidal SiQDs [6]. The room-temperature visible light emission from nanoscale PSi was first demonstrated by Canham [6], which was attributed to the effect of quantum confinement. It has been reported that electrochemically etched PSi obtained from p-or n-type Si wafers in various solvents (such as methanol, water, ethanol, acetone, and toluene) upon ultrasonication can form abeyance of SiQDs. The abeyance constitutes a broad size distribution in the range of micrometers to nanometers. In addition, it is possible to achieve tiny SiQDs in a size range of $2-11 \mathrm{~nm}$ by controlling the sieve $(20 \mathrm{~nm})$ together with prolonged ultrasonication of PSi [7]. It is established that the indirect bandgap of bulk $\mathrm{Si}$ is transformed into a direct or quasi-direct one when the size of the sample becomes comparable to or below the bulk exciton Bohr radius $(\sim 5 \mathrm{~nm})$, wherein the quantum yield (QY) can reach up to $90 \%$ due to the quantum size effect [7]. The optical and electrical attributes of SiQDs can be improved by modifying the surface morphology (sizes and shapes of particles), chemical bonding, and via doping with the transition metals [8]. Additionally, the incorporation of $\mathrm{ZnO}$ into the PSi was shown to significantly enhance the room-temperature visible photoluminescence (PL) emission intensity as much as seven-fold [9]. The bandgap energy displays an inverse correlation with the size of the SiQDs, and the emission wavelength reveals a blue shift as the size of the SiQDs reduces, which can be ascribed to the effect of strong quantum confinement [9]. It is worth noting that the previous report on the electrochemically etched synthesis of SiQDs revealed the difficulty of attaining uniform sizes [10]. To surmount this limitation, ammonium hydroxide $\left(\mathrm{NH}_{4} \mathrm{OH}\right)$ was used for preparing spherical nanoparticles such as Si [11], titanium dioxide [12], silver [13], magnetite [14] and ZnO by the assembly of tiny nanoparticles [13].

In addition, strong bases, including $\mathrm{KOH}$ and $\mathrm{NaOH}$, plus weak bases, such as $\mathrm{NH}_{4} \mathrm{OH}$, were used to grow tiny core-shell nanoparticles [15]. Despite many dedicated efforts, the production of high-quality $\mathrm{ZnO}$ incorporated core-shell SiQDs (ZnSiQDs) with customized properties remains challenging. This motivates us, in this work, to prepare $\mathrm{ZnSiQDs}$ in acetone using electrochemical etching of a $\mathrm{Si}$ wafer following the protocols referred to in [16]. The influence of different amounts of $\mathrm{NH}_{4} \mathrm{OH}$ addition (15 to $25 \mu \mathrm{L}$ ) on the morphology and optical (room temperature absorbance and PL emission) characteristics of the as-prepared $\mathrm{ZnSiQD}$ suspension were evaluated. The sizes and optical properties of these QDs were shown to significantly depend on the $\mathrm{NH}_{4} \mathrm{OH}$ contents, indicating the feasibility of tailoring the room temperature PL properties by adjusting the amount of $\mathrm{NH}_{4} \mathrm{OH}$ [17].

Previously, various metal elements (including $\mathrm{Cr}^{+3}$ and $\mathrm{V}_{2} \mathrm{O}_{5}$ ) were incorporated into the PSi film by immersing them in a solvent to improve the PL of the PSi. Furthermore, the PSi surface was coated with various metals of varying thicknesses to alter the overall properties. It was also assumed that by doping SiQDs with various transition metals, one could alter their microstructures and morphologies, thereby improving their optical proper [18-20]. It was proposed that the incorporated transition metals act as a host substratum in the PSi, improving the visible PL emission traits [20]. It is renowned that each of these metallic elements possessing 18 core electrons and 6 valence electrons in the $3 p$ shell shows several characteristics when doped; the number of electrons differs to the degree that they can turn into the active outermost $3 \mathrm{~d}$ electrons, hence participating in 
the optical transitions with relaxed selection rules [21]. In an attempt to enhance optical characteristics, high-quality PSi integrated with Zn powder was synthesized in a single step. The transition metal $\mathrm{Zn}$ was chosen because it belongs to the transition metals that served as the host substrate [20], it dissolves directly in HF, and it combines with $\mathrm{O}$ to form $\mathrm{ZnO}$. The optical properties of colloidal SiQDs derived from PSi are primarily due to the effects of quantum confinement, ligands, and various surface chemistries, as well as surface defects, which produce new energy levels in the bandgap region, facilitating radiative recombination of $\left(\mathrm{e}^{-}-\mathrm{h}^{+}\right)$pairs [22,23].

The intrinsic states may be reduced as the size of the quantum dots (QDs) and the number of atoms in the dots increase. When the relative position of these intrinsic states in the band diagram becomes lower than the edge state, there is a loss of expected emission. The offset between energy levels (surface states and band position) that determine optical properties is one of the important parameters. The fluorescence effect differs between small and large QDs. It can be seen that the offset between surface states and LUMO is greater for small QDs than for large QDs. In this case, the emission wavelength is determined by the excitation wavelength. Moreover, as the size of the dots increases, such a reliance degrades, and bandgap-mediated transitions start increasing. Excitation-independent emission behavior is caused by the obstructing of surface state-based transitions and the appearance of some functional groups. It has been shown that QDs such as carbon dots (CDs) with amino-rich surface groups exhibit less dependence on excitation wavelength due to surface state passivation [23] Bands are established in standard semiconductors such as $\mathrm{Si}$ by the partnership of neighboring energy levels of a very large number of atoms and molecules. Nevertheless, as the particle size approaches the nano-size and the amount of atoms and molecules drops rapidly, the number of intersecting energy levels reduces, allowing the band to widen, and the energy levels become discrete and quantized. Because QDs are so small, they have a larger energy gap between the valence and conduction bands than bulk states. The quantum confinement and discrete energy levels effect are two main features for QDs. As a result, the characteristics of quantum dots vary with their size, and their excitations are confined in all three-dimensional space. The major feature of a quantum dot that describes the relationship between QD size and the wavelength of light they generate is confinement energy [24]. Figure 1 illustrates the effect of size-changing from bulk to quantum size on the electronic level and the bandgap value. The special characteristics of QDs, which are caused by their unusually high surface-to-volume ratios, clarify why these nanocrystals can produce different colors based on the size of particles. As the particle size decreases, the energy levels in the conduction band (CB) and the valance band (VB) become discrete (quantized), as exemplified in Figure 1. Thereby, so much energy is required to excite the particle, and more energy is dissipated when the quantum dot returns to its state of relaxation. If the size of quantum dots is changed, they will produce any color of light within the same material [25]. 


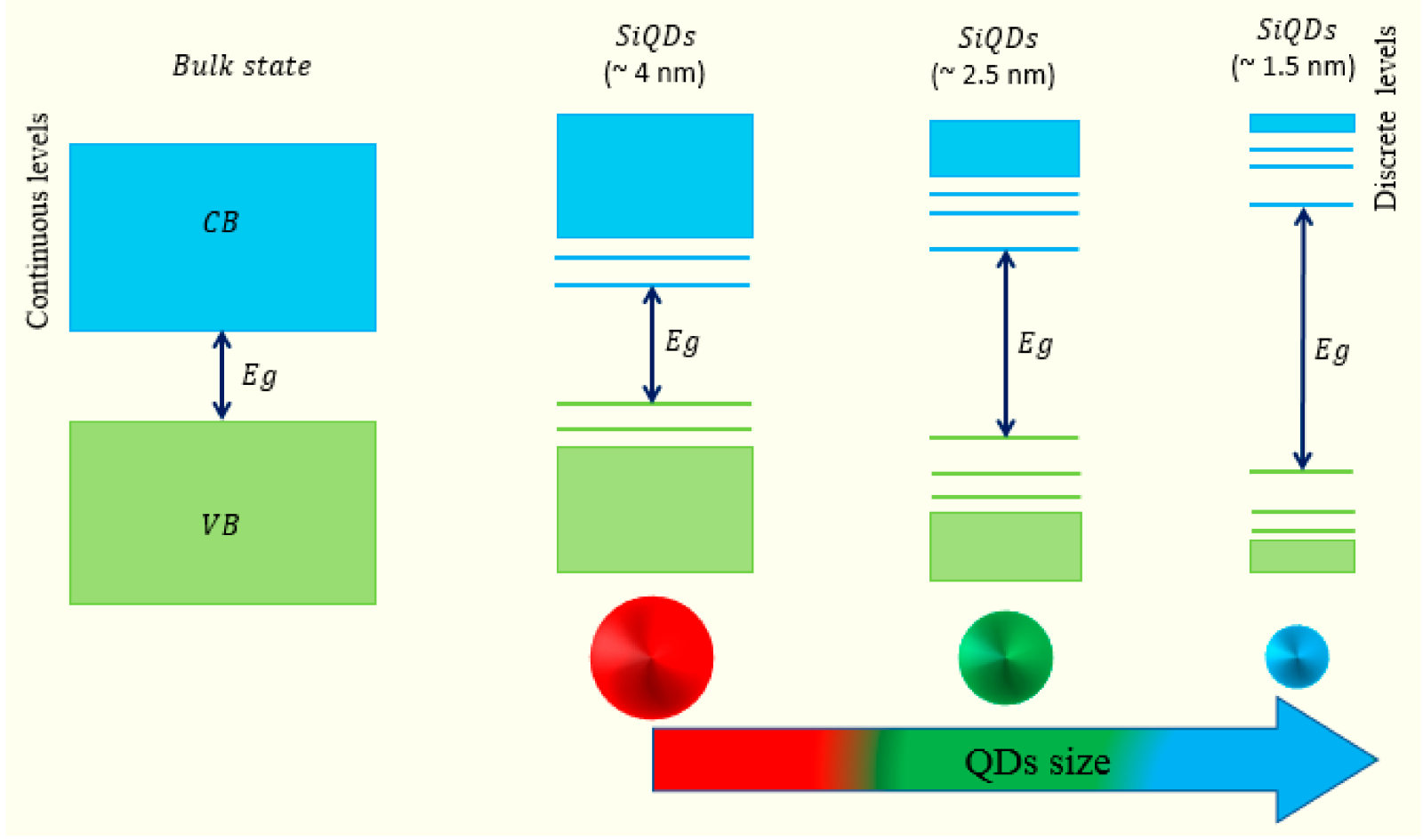

Figure 1. Schematic depiction of how the change from the bulk to the QDs impact the CB, VB levels, and Eg in QDs.

2. Materials and Methods

2.1. Materials

High-purity $(99.99 \%)$ chemical reagents of hydrogen fluoride $(\mathrm{HF})$, ethanol $\left(\mathrm{C}_{2} \mathrm{H}_{5} \mathrm{OH}\right)$, zinc $(\mathrm{Zn})$ powder, acetone $\left(\mathrm{C}_{3} \mathrm{H}_{6} \mathrm{O}\right), \mathrm{NH}_{4} \mathrm{OH}(28.0$ to $30.0 \%)$ were purchased from SigmaAldrich Chemical Co. (St. Louis, MI, USA). n-type Si (100) (thickness and resistivity in the range of 355-405 $\mu \mathrm{m}$, and 0.002-0.005 $\Omega . \mathrm{cm}$, respectively) were used to synthesize the PSi incorporated with $\mathrm{Zn}$ (ZnPSi) and colloidal Si quantum dots (SiQDs) combined with zinc (ZnSiQDs following the method prescribed in $[9,16]$.

\subsection{Preparation of ZnPSi and Suspension $\mathrm{ZnSiQDs}$ in the Presence/Absence of $\mathrm{NH}_{4} \mathrm{OH}$}

N-type (100) Si wafer was cut via a diamond cutter in rectangles of dimensions $1.5 \mathrm{~cm} \times 2.5 \mathrm{~cm}^{2}$. The Radio Corporation of America (RCA) process was used to clean and remove the native oxide from the Si chips [16]. In the ring-etching cell (made of Teflon), the Zn powder of mass of $0.17 \mathrm{~g}$ was added in a mixture of HF and ethanol at a volume ratio of 1:1. To form the ZnPSi film, n-type Si (100) acts as an anode, while platinum (Pt) wire acts as a cathode and is immersed in the HF/ethanol solution. The etching cell was illuminated via a tungsten lamp through the etching method conducted at various current densities ( 5 to $45 \mathrm{~mA} / \mathrm{cm}^{2}$ with the step of $5 \mathrm{~mA} / \mathrm{cm}^{2}$ ); the optimum properties of ZnPSi were achieved when the etching current density was $5 \mathrm{~mA} / \mathrm{cm}^{2}$. After electrochemical etching was completed, a circular disk of brown color was produced on the Si substrate. In addition, an orange-red light was emitted from the brown disk under excitation wavelength (UV light). The electropolishing was utilized to separate the ZnPSi from the n-Si substrate. A high current density value was applied; brown pieces of ZnPSi film were collected by centrifugation for the HF/ethanol (at $1000 \mathrm{rpm}$ to $5 \mathrm{~min}$ ). The resultant brown pieces were ultrasonicated in acetone for $60 \mathrm{~min}$ to generate a grey solution via filtration and centrifugation (at $1500 \mathrm{rpm}$ for $30 \mathrm{~min}$ ); colloidal ZnSiQDs in acetone solution was obtained. The previous steps formed the top-down method of production of the ZnSiQDs. The following steps include the bottom-up approach to the re-growth of the $\mathrm{ZnSiQDs}$. First, different amounts of $\mathrm{NH}_{4} \mathrm{OH}(15,20$, and $25 \mu \mathrm{L})$ were added to the 
colloidal ZnSiQDs suspended in acetone and incubated in a dark place for $72 \mathrm{~h}$. Then, under the ultra-violet (UV) light influence, various colors were emitted from suspension ZnSiQDs with NH4OH. Finally, to fix the size of colloidal ZnSiQDs with $\mathrm{NH}_{4} \mathrm{OH}, 1 \mu \mathrm{L}$ of polyvinylpyrrolidone (PVP) was added to $40 \mu \mathrm{L}$ of DI water and mixed with $20 \mathrm{~mL}$ colloidal $\mathrm{ZnSiQDs}$ with $\mathrm{NH}_{4} \mathrm{OH}$ in acetone; the mixture was stirred for $30 \mathrm{~min}$. As-prepared samples were characterized at room temperature.

\subsection{Characterization of ZnPSi and ZnSiQDs Colloids}

X-ray diffractometer (Bruker D8 Advance, AXS GmbH, Karlsruhe, Germany) was utilized to study the crystallinity of the ZnPSi films, with the $\mathrm{Cu} \mathrm{K} 1$ line of wavelength $1.54 \AA$ being used. The morphology of the colloidal ZnSiQD suspension was analyzed using an energy-filtered transmission electron microscope (EFTEM, Libra 120, Zeiss GmbH, Oberkochen, Germany). UV-vis-NIR absorption spectroscopy (Cary 5000, Agilent, CA, USA) was used to record the absorption spectra of the colloidal ZnSiQD suspension. The photoluminescence spectrometer attached with HPC-2 collimated light source was used to measure the emission spectra of the samples (at the excitation wavelength, $\lambda_{\text {exc }}=325$, 365,390 , and $425 \mathrm{~nm}$ ). The field emission scanning electron microscope (FESEM, FEI Nova SEM 450, FEI Company, Hillsboro, OR, USA) was used to image the morphology of the samples. The trace elements in the $\mathrm{ZnSiQD}$ suspension were detected using the energy-dispersive X-ray (EDX) spectrometer. A Bruker optics FT-IR spectrometer model (Tensor 27, Bruker Optics Ltd., Coventry, UK) was utilized to capture Fourier transform infrared (FTIR) spectra. The survey spectrum of X-ray photoelectron spectroscopy (XPS) was measured using a monochromatic Al Ka supply prepared Kratos Axis Ultra DLD device (Kratos Analytical Ltd., Manchester, UK).

\section{Results and Discussion}

\subsection{Morphology and Structure of ZnPSi}

Figure 2 illustrates the FESEM image together with their PL of ZnPSi etched at the current density of $5 \mathrm{~mA} / \mathrm{cm}^{2}$; a high number of pores were achieved at $5 \mathrm{~mA} / \mathrm{cm}^{2}$. Weight measurements can easily estimate porosity, defined as the fraction of vacancy within the PSi layer. The porosity of the ZnPSi was determined using the gravimetric relation [26]:

$$
\text { Porosity }(\%)=\frac{m 1-m 2}{m 1-m 3} \times 100 \%
$$

where $m_{1}$ is the mass of the samples before etching, $m_{2}$ is the mass of the samples after etching, and $m_{3}$ is the mass of the samples after removing the PS layer with $\mathrm{KOH}$ solution. The PSi thickness can be calculated by Equation [26]:

$$
\text { Thickness }=\frac{m 1-m 3}{\rho S}
$$

where the $\rho$ and $S$ are the Si density and ZnPSi area, respectively. The area of ZnPSi was $3.14 \mathrm{~cm}^{2}$ at a diameter of $2 \mathrm{~cm}$, and the Si density was $2.33 \mathrm{~g} / \mathrm{cm}^{3}$. The PL is proportional to the porosity; when the porosity increased, the PL shifted to short-wavelength due to a decrease in the bandgap, which was a result of the reduced crystallite size $[27,28]$.

Figure 3 shows the XRD analysis for ZnPSi etched at $5 \mathrm{~mA} / \mathrm{cm}^{2}$ at diffraction angles

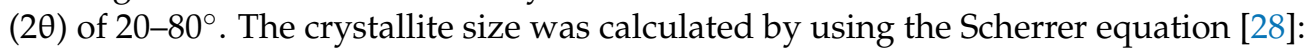

$$
D=\frac{K \lambda}{\beta * \cos (\theta)}
$$

$D$ : grain size, $K$ : constant (0.9), $\lambda$ : XRD wavelength, $\theta$ : Bragg angle, and $\beta$ : full width, half maximum (FWHM) for XRD peaks. Figure 3a shows the crystallite size Si before and after etching of $160 \mathrm{~nm}$ and $2.44 \mathrm{~nm}$, respectively, due to the change in the morphology of $\mathrm{Si}$ after etching. Figure $3 \mathrm{~b}$ reveals the generation of $\mathrm{ZnO}$ and $\mathrm{Si}$ nanostructure; the crystallite 
size of $\mathrm{ZnO}$ is $25.65 \mathrm{~nm}$. The sharp crystallite size was reduced because of the generation of pore layers with high porosity and small wall thicknesses. Referring to Figure 1 and the result in Figure 2, the PL of ZnPSi is related to the quantum confinement effect because the Si crystallite size is less than $10 \mathrm{~nm}[29,30]$.

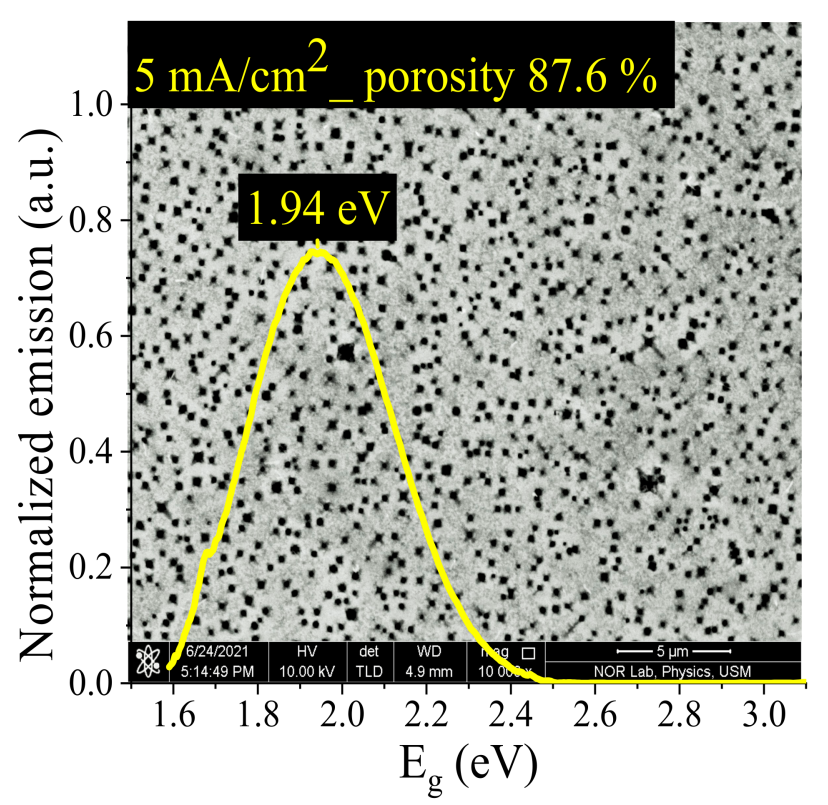

Figure 2. FESEM morphology combined with PL of the PSi etched at $5 \mathrm{~mA} / \mathrm{cm}^{2}$.
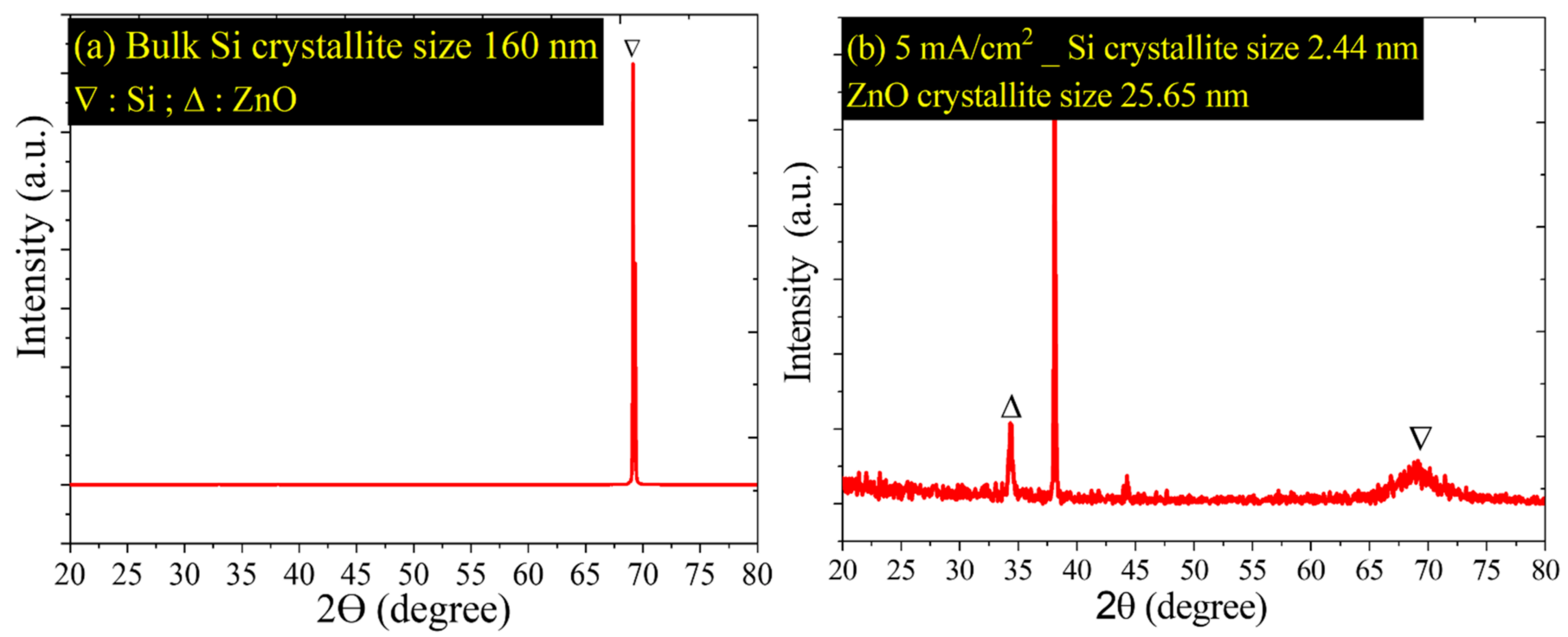

Figure 3. XRD analysis for (a) bulk Si; (b) ZnPSi at etching current density of $5 \mathrm{~mA} / \mathrm{cm}^{2}$.

Figure 4 illustrates the FTIR spectrum of native (control) PSi and PSi incorporating $\mathrm{Zn}$ (ZnPSi). The control PSi has peaked at $616 \mathrm{~cm}^{-1}, 1083 \mathrm{~cm}^{-1}, 2113.5 \mathrm{~cm}^{-1}$, and (3000-4000 $\left.\mathrm{cm}^{-1}\right)$, which refer to bonds of Si-Si, Si-O-Si, Si-H, and Si-OH, respectively, while ZnPSi has peaked at $457 \mathrm{~cm}^{-1}, 615 \mathrm{~cm}^{-1}$, and $903 \mathrm{~cm}^{-1}$, which refer to bonds of $\mathrm{Zn}-\mathrm{O}, \mathrm{Si}-\mathrm{Si}$, and Si-O-Zn, respectively [31-33]. The peaks centred at 1057, 2112.5, and $2921 \mathrm{~cm}^{-1}$ of ZnPSi vanished due to the generated $\mathrm{ZnO}$ shell, which prevents oxidation of the SiQDs; also, the new sharp peaks at $457 \mathrm{~cm}^{-1}$ and $904 \mathrm{~cm}^{-1}$ refer to the stretching band of $\mathrm{ZnO}$ because of the $\mathrm{ZnO}$ shell produced around SiQDs. It was reported that the addition of $\mathrm{Zn}$ powder to the electrolyte during the electrochemical etching could produce 
$\mathrm{ZnO}$ on the surface of SiQDs. The structure of the compound semiconductor is core and shell; the wider bandgap semiconductor (shell) acts as a potential barrier for the narrower bandgap (core) [34,35]. However, the production of $\mathrm{Zn}-\mathrm{O}$ and Si-O-Zn can demonstrate that $\mathrm{Zn}^{+2}$ ions were successfully doped into the inner SiQDs layer and that the SiQDs layer was fully coated [35].

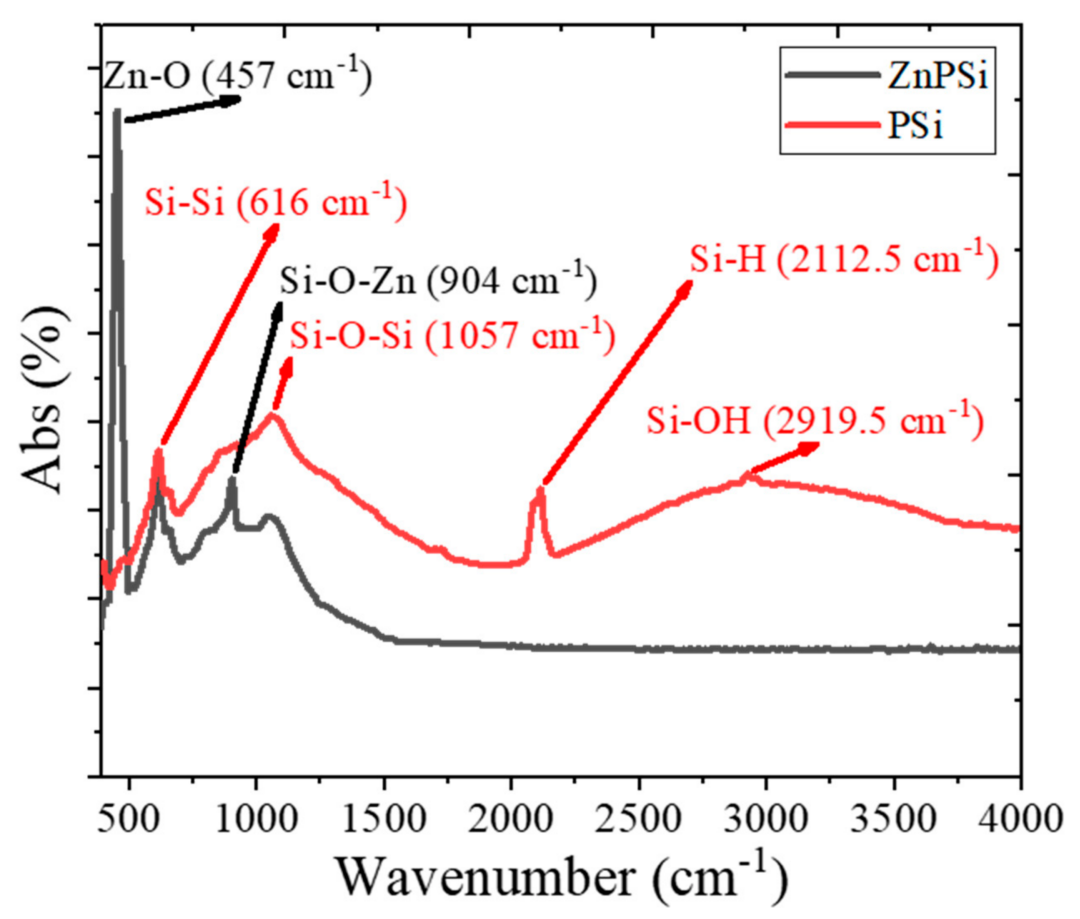

Figure 4. FTIR spectra of Psi and ZnPSi.

Figure 5 shows the XPS profiles of the $\mathrm{ZnPSi}$, which verified the presence of elements such as $\mathrm{Zn}, \mathrm{F}, \mathrm{Si}$, and $\mathrm{O}$. The existence of $\mathrm{Zn}$ and $\mathrm{O}$ on the surface and in the channels of the porous layer led to the formation of $\mathrm{Zn}-\mathrm{O}$ and Si-O linkages. Thus, the O1s peak can be fitted with two components, including Zn-O and Si-O linkages [36,37]. Figure 6 depicts the EDX spectral analysis of the prepared $\mathrm{ZnPSi}$ with $0.17 \mathrm{~g}$ of $\mathrm{Zn}$. The elemental traces (weight \%) in the ZnPSi are shown in the included table attached to the image.

(a) Si $2 p$

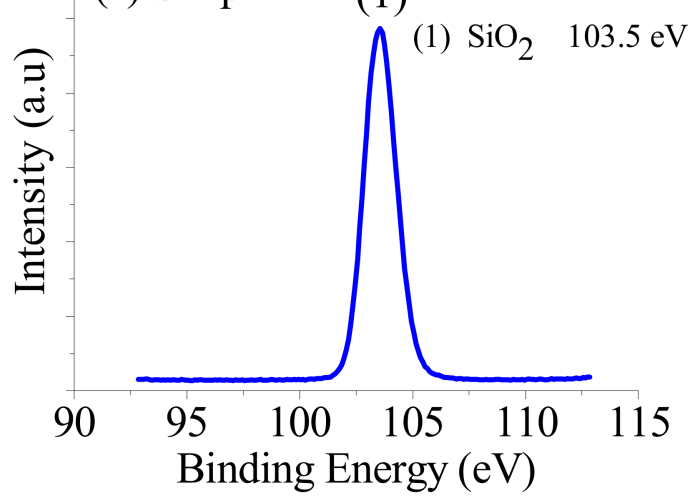

(b) $\mathrm{O} 1 \mathrm{~s}$

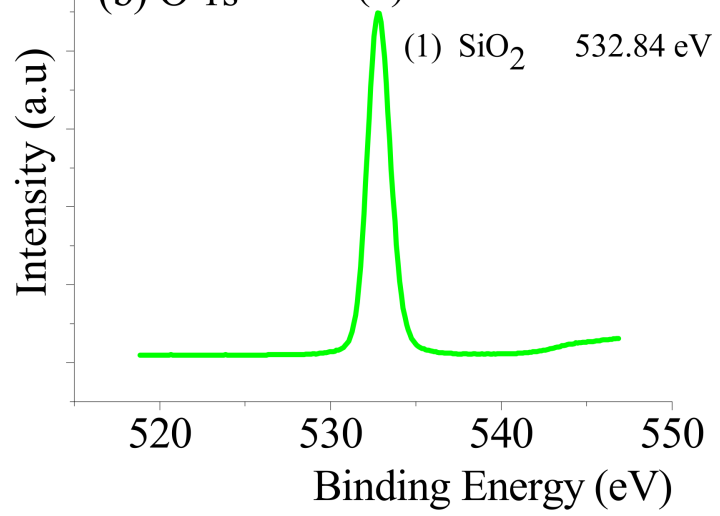

Figure 5. Cont. 
(c) $\mathrm{Zn} 2 \mathrm{p}$

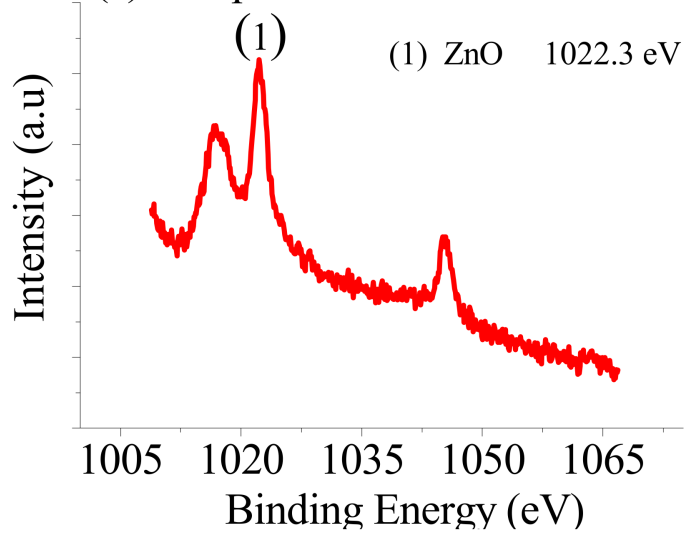

Figure 5. The XPS profile of the ZnPSi for (a) Si2p (103.5 eV), (b) O1s (532.84 eV), and (c) Zn2p (1022.3 eV).

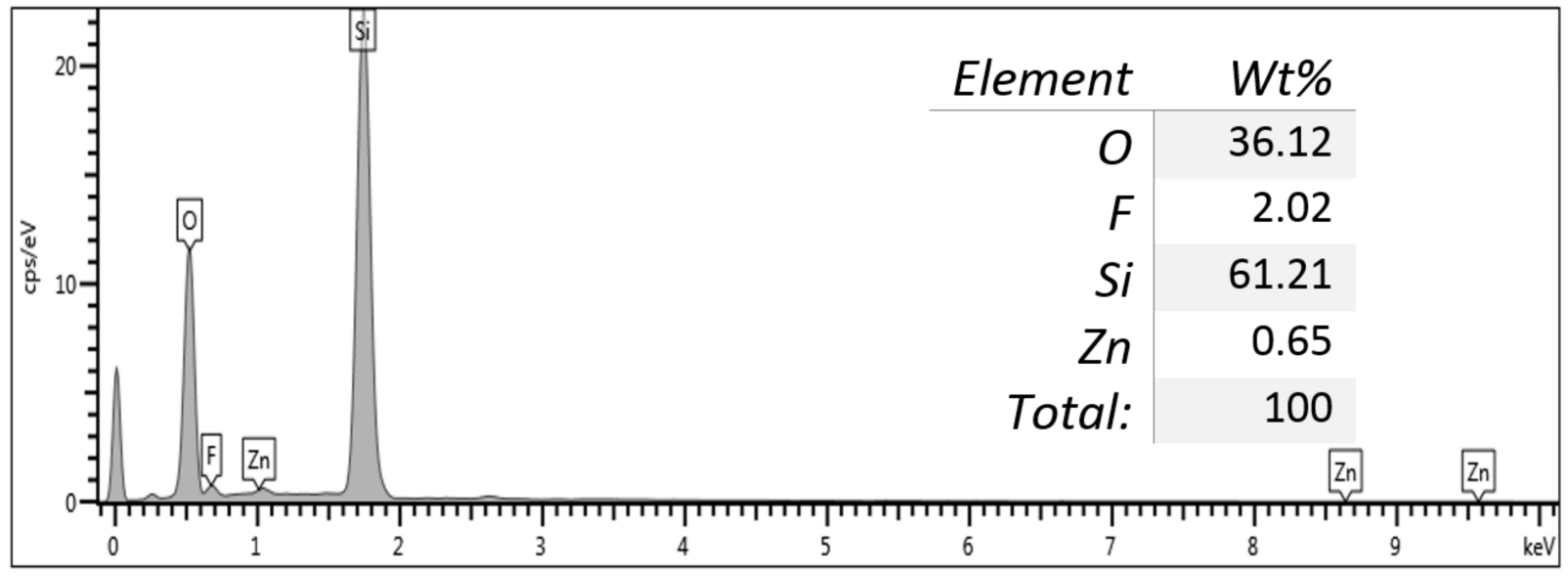

Figure 6. EDX images of the prepared ZnPSi with $0.17 \mathrm{~g}$ of included $\mathrm{Zn}$.

\subsection{Morphology and Structure of ZnSiQDs}

Figure $7 \mathrm{a}-\mathrm{d}$ show the EFTEM micrographs, and Figure $7\left(\mathrm{a}_{1}-\mathrm{d}_{1}\right)$ show particle size distributions of the colloidal $\mathrm{ZnSiQDs}(20 \mathrm{~mL})$ suspended in acetone without (a) and with $\mathrm{NH}_{4} \mathrm{OH}$ (b,c, and d) of $15 \mu \mathrm{L}, 20 \mu \mathrm{L}$, and $25 \mu \mathrm{L}$, respectively. Samples prepared without and with $\mathrm{NH}_{4} \mathrm{OH}$ showed the nucleation of spherically shaped $\mathrm{ZnSiQDs}$ (yellow circle) with the corresponding mean size of $1.22 \mathrm{~nm}$ and 2.1, 2.77, and $7.4 \mathrm{~nm}$. The dimensions of QDs enlarged with the addition of $\mathrm{NH}_{4} \mathrm{OH}$, indicating the strong influence of $\mathrm{NH}_{4} \mathrm{OH}$ on the aggregation, nucleation, and growth of the tiny $\mathrm{ZnSiQDs}$. In short, the sizes and shapes of the $\mathrm{ZnSiQDs}$ were significantly affected by the $\mathrm{NH}_{4} \mathrm{OH}$, wherein the QDs size distribution became more uniform, and the inter-particle separation was reduced. The inclusion of $\mathrm{NH}_{4} \mathrm{OH}$ in the colloidal $\mathrm{ZnSiQD}$ suspension enabled the re-growth of the smaller particles to form the chain by producing a core centre [38]. In this study, the size of $\mathrm{ZnSiQDs}$ was minuscule, between 1.22 and $7.4 \mathrm{~nm}$, so to determine the major shape of these particles, an EFTEM image was completed again for the largest particles with low concentrations to obtain an image with high resolution; the particles have an approximately spherical shape, as shown in Figure 7e. The tiny particles (a yellow circle of Figure 7e) unioned to generate the large particle, as shown in the image on the left of Figure 7e. That particle has two regions; the first part is the core (blackish point), the second part is the shell around the core. Thus, this image supports the hypothesis of the generated core/shell between SiQDs and $\mathrm{ZnO}$. 

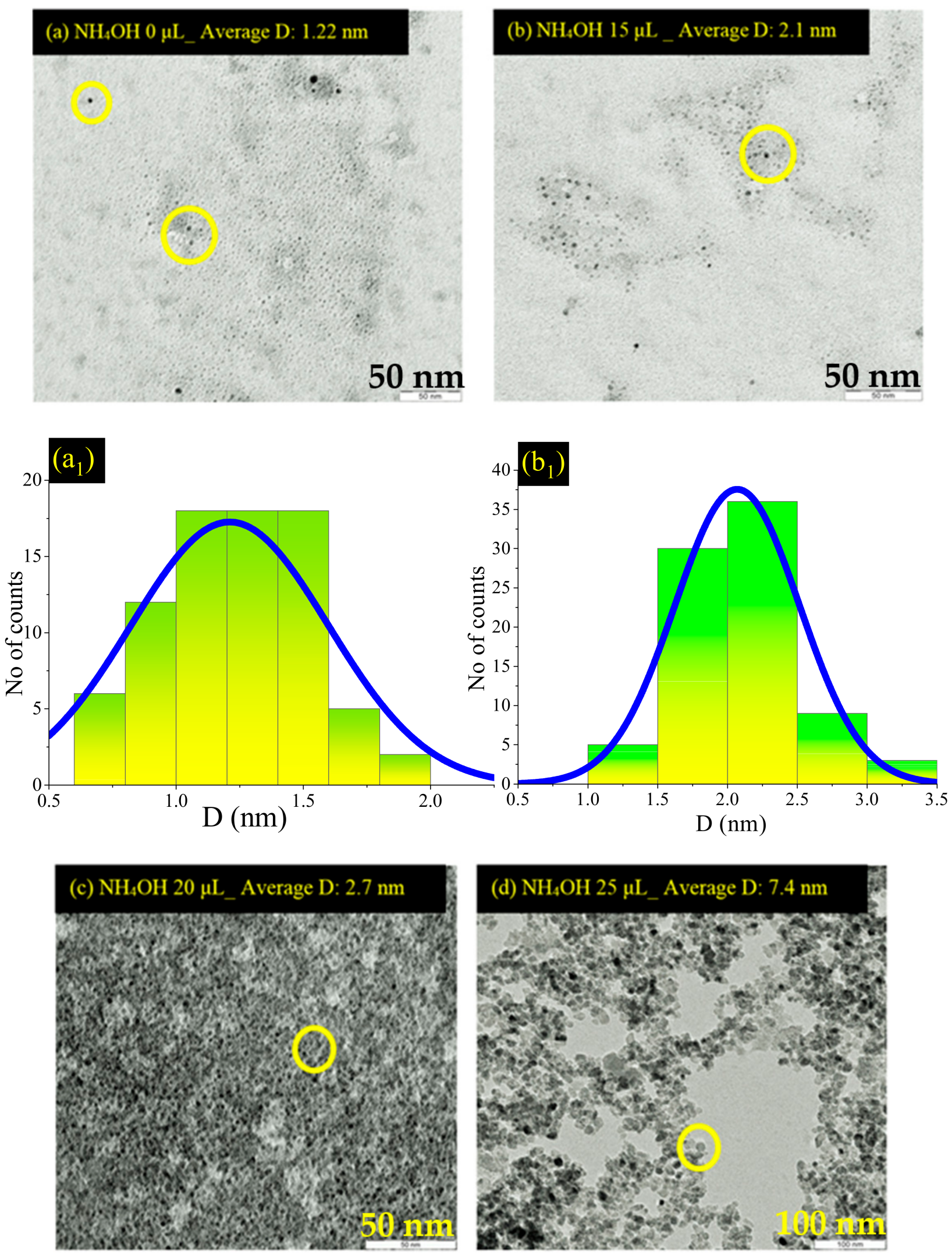

Figure 7. Cont. 

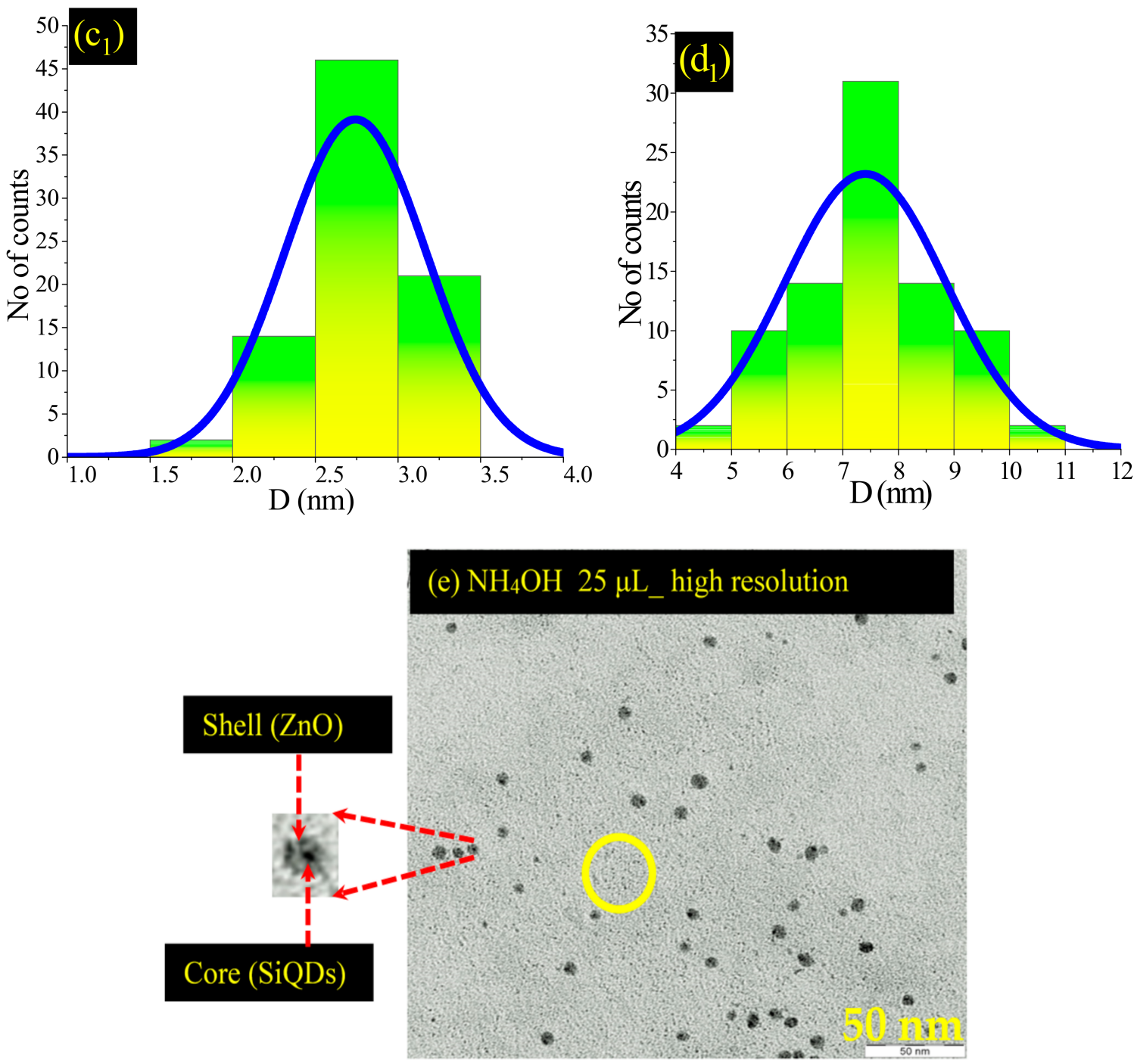

Figure 7. (a-d) EFTEM images of the colloidal ZnSiQD suspension in acetone prepared with $\mathrm{NH}_{4} \mathrm{OH}$ of $0,15,20$, and $25 \mu \mathrm{L}$, respectively. $\left(\mathbf{a}_{\mathbf{1}}-\mathbf{d}_{\mathbf{1}}\right)$ particle size distributions of the colloidal ZnSiQDs $(20 \mathrm{~mL})$ suspended in acetone with $\mathrm{NH}_{4} \mathrm{OH}$ of 0,15 , 20, and $25 \mu \mathrm{L}$, respectively. (e) $\mathrm{NH}_{4} \mathrm{OH}: 25 \mu \mathrm{L}$ high resolution.

\subsection{Optical Characteristics of ZnSiQDs}

Figure 8a-f illustrate fluorescence from the $\mathrm{ZnSiQDs}$ prepared with different amounts of $\mathrm{NH}_{4} \mathrm{OH}$ under the excitation wavelength of $365 \mathrm{~nm}$ and $425 \mathrm{~nm}$, respectively. The obtained colloidal ZnSiQDs showed strong green, blue, and yellow-orange emissions. Furthermore, the luminescence brightness of these $\mathrm{ZnSiQDs}$ was enhanced with the increase in $\mathrm{NH}_{4} \mathrm{OH}$ contents. This indicated the significant role of $\mathrm{NH}_{4} \mathrm{OH}$ that controlled the QDs size by producing the core center to re-grow these QDs from tiny sizes, thereby achieving the uniform-sized QDs with narrow size distributions. Moreover, the excitation wavelengths' independence of the luminescence brightness verified the uniform size distribution of the majority of the suspended QDs. For example, the sample $(20 \mathrm{~mL})$ containing colloidal $\mathrm{ZnSiQDs}$ with $20 \mu \mathrm{L}$ of $\mathrm{NH}_{4} \mathrm{OH}$ added exhibited the same green emission brightness under the excitation of $365 \mathrm{~nm}$ and $425 \mathrm{~nm}$, respectively (Figure $8 \mathrm{~b}$, and f(IV) or g(IV)). The sample $(20 \mathrm{~mL})$ containing colloidal $\mathrm{ZnSiQDs}$ with $15 \mu \mathrm{L}$ of $\mathrm{NH}_{4} \mathrm{OH}$ added displayed a similar blue emission brightness when excited with $365 \mathrm{~nm}$ and $425 \mathrm{~nm}$, respectively (Figure 8a,g(II)). 

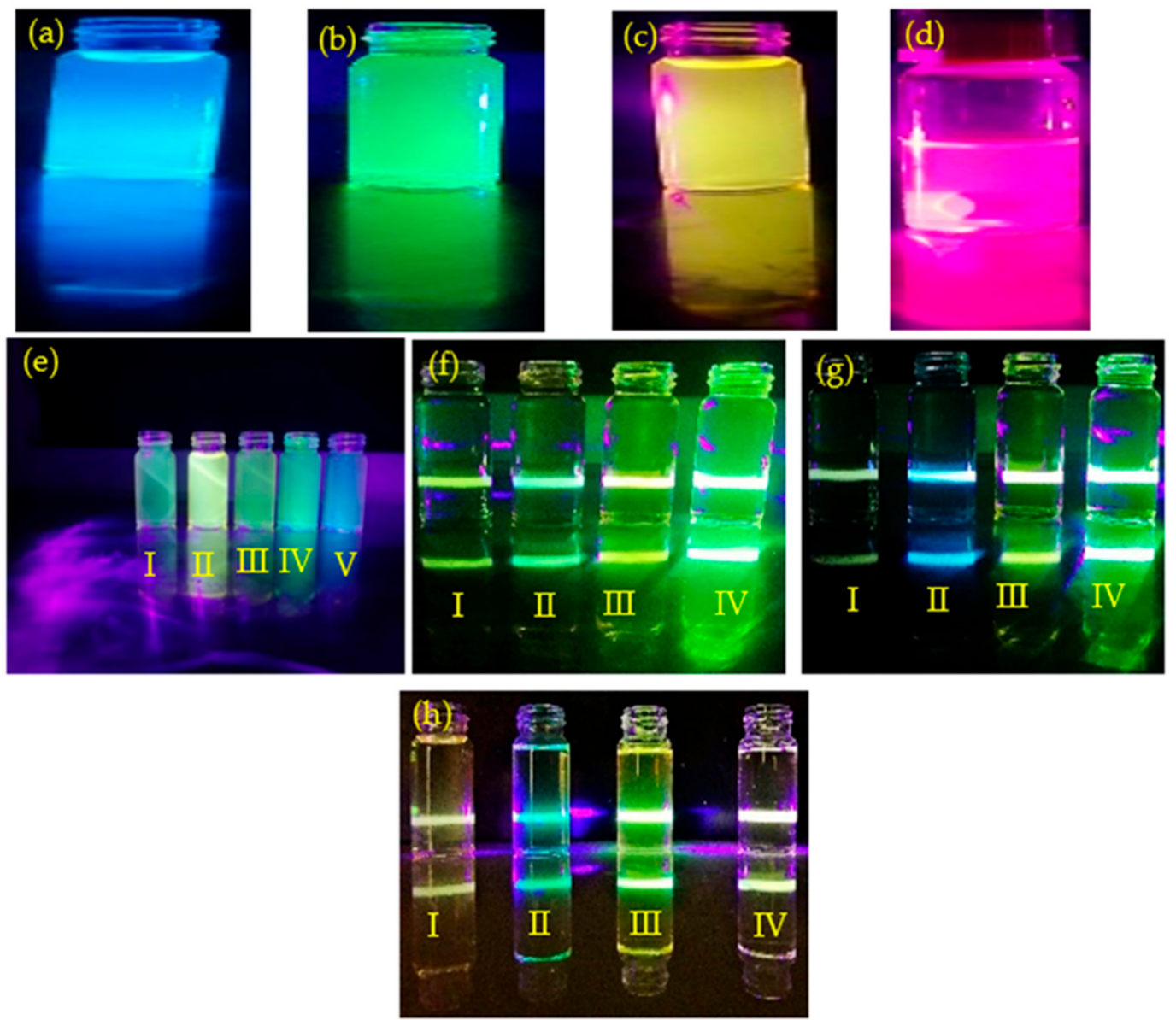

Figure 8. Luminescence from colloidal $\mathrm{ZnSiQDs}$ containing various amounts of $\mathrm{NH} 4 \mathrm{OH}$ under different excitation (a-d) added with $15 \mu \mathrm{L}, 20 \mu \mathrm{L}, 25 \mu \mathrm{L}$, and $30 \mu \mathrm{L}$ of $\mathrm{NH}_{4} \mathrm{OH}$ excited at $365 \mathrm{~nm}$, respectively; (e) bottles I, II, III, IV, and V with $17 \mu \mathrm{L}, 25 \mu \mathrm{L}, 19 \mu \mathrm{L}, 20 \mu \mathrm{L}$, and $15 \mu \mathrm{L}$ of $\mathrm{NH}_{4} \mathrm{OH}$ excited at $365 \mathrm{~nm}$ added, respectively; (f) bottles I, II, III, and IV with $17 \mu \mathrm{L}, 19 \mu \mathrm{L}, 22 \mu \mathrm{L}$, and $20 \mu \mathrm{L}$ of $\mathrm{NH}_{4} \mathrm{OH}$ excited at $410 \mathrm{~nm}$ added, respectively; (g) bottles I, II, III, and IV with $17 \mu \mathrm{L}$, $15 \mu \mathrm{L}, 22 \mu \mathrm{L}$, and $20 \mu \mathrm{L}$ of $\mathrm{NH}_{4} \mathrm{OH}$ excited at $410 \mathrm{~nm}$ added, respectively; (h) bottles I, II, III, and IV with $16 \mu \mathrm{L}, 15.5 \mu \mathrm{L}$, $21.5 \mu \mathrm{L}$, and $14 \mu \mathrm{L}$ of $\mathrm{NH}_{4} \mathrm{OH}$ excited at $410 \mathrm{~nm}$ added, respectively.

Figure 9a,b show the UV-Vis-NIR absorption spectra of the colloidal ZnSiQD suspension $(20 \mathrm{~mL})$ in acetone without and with $\mathrm{NH}_{4} \mathrm{OH}(20 \mu \mathrm{L})$ addition. The absorption intensity was improved by 2.5 times, and the peak was shifted to a longer wavelength (from $300 \mathrm{~nm}$ to around $330 \mathrm{~nm}$ ), indicating the formation of larger particles or an increase in the density of the particles $[39,40]$. The inclusion of $\mathrm{NH}_{4} \mathrm{OH}$ led to the rise in the growth of the nanoparticles, wherein the $\mathrm{ZnSiQDs}$ prepared with $\mathrm{NH}_{4} \mathrm{OH}$ showed higher absorbance than the one prepared without $\mathrm{NH}_{4} \mathrm{OH}$. The inset displays the Tauc plot used to evaluate the optical bandgap energy $\left(\mathrm{E}_{\mathrm{g}}\right)$ of the $\mathrm{ZnSiQDs}$. For both samples, the absorbance was dropped as the wavelength was increased. The higher absorption intensity for the ZnSiQDs containing $\mathrm{NH}_{4} \mathrm{OH}$ can be attributed to the higher transition probability because of the higher electronic density of states in the QDs. The value of $\mathrm{E}_{\mathrm{g}}$ for the $\mathrm{ZnSiQDs}$ without and with $\mathrm{NH}_{4} \mathrm{OH}$ inclusion was approximately $3.6 \mathrm{eV}$ and $3.35 \mathrm{eV}$, respectively. The observed reduction in the value of $\mathrm{E}_{\mathrm{g}}$ for the $\mathrm{ZnSiQDs}$ containing $\mathrm{NH}_{4} \mathrm{OH}$ can be ascribed to the QDs' size enlargement.

Figure 10 shows the PL spectra (excited at $325 \mathrm{~nm}$ ) of the colloidal $\mathrm{ZnSiQD}$ suspension $(20 \mathrm{~mL})$ in acetone without and with $\mathrm{NH}_{4} \mathrm{OH}(20 \mu \mathrm{L})$ inclusion, indicating the visible emission in the blue and green region. The PL spectra of the ZnSiQDs without and with $\mathrm{NH}_{4} \mathrm{OH}$ exhibited a prominent fluorescence emission peak at $411 \mathrm{~nm}$ (blue) and $539 \mathrm{~nm}$ (green), respectively. Referring to the $\mathrm{ZnSiQDs}$ without $\mathrm{NH}_{4} \mathrm{OH}$, the observed intense 
emission peaks of the ZnSiQDs at 411 that originated from the core consisted of pure SiQDs [41], while the peak at $539 \mathrm{~nm}$ was related to the defects in the ZnO shell [42,43]. The $\mathrm{ZnSiQDs}$ containing $\mathrm{NH}_{4} \mathrm{OH}$ showed a weak peak at $411 \mathrm{~nm}$ and a strong peak at $539 \mathrm{~nm}$. The difference in peak intensity after the addition of $\mathrm{NH}_{4} \mathrm{OH}$ was due to the formation of a $\mathrm{ZnO}$ shell around SiQDs core. Due to the SiQDs surface passivation by $\mathrm{ZnO}$, the emission from the core was damped or hindered. In addition, the excess amount of $\mathrm{NH}_{4} \mathrm{OH}$ could also affect the fluorescence emission from $\mathrm{ZnSiQDs}$, leading to a red-shift in the peak emission wavelength from blue $(411 \mathrm{~nm})$ to green $(539 \mathrm{~nm})$. The growth of $\mathrm{NH}_{4} \mathrm{OH}$-activated $\mathrm{ZnSiQDs}$ led to an increase in the particle size, narrowing the bandgap accompanied by a red shift in the emission peak.

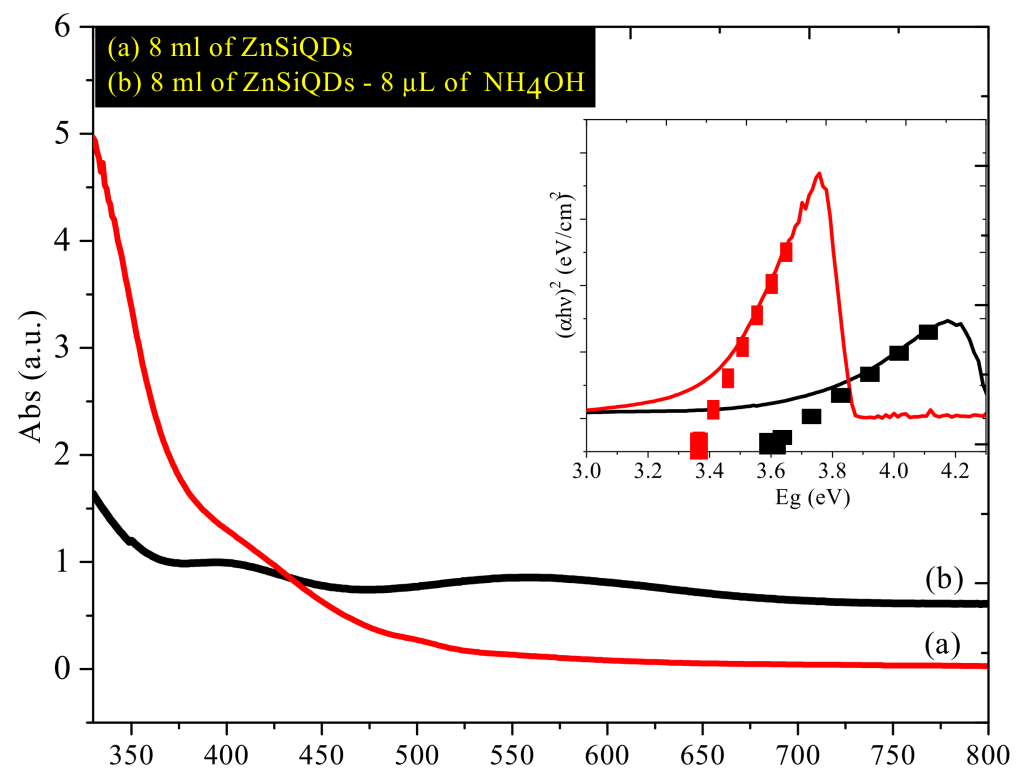

Figure 9. ZnSiQD suspension in acetone prepared (a) without and (b) with $\mathrm{NH} 4 \mathrm{OH}$ (Inset: Tauc plot for the bandgap estimation.

Figure 11 depicts the PL spectra of the colloidal ZnSiQD suspension in acetone (under $365 \mathrm{~nm}$ excitation) synthesized with different amounts of $\mathrm{NH}_{4} \mathrm{OH}$ (15 to $25 \mu \mathrm{L}$ ), wherein the bottles in the inset show the corresponding blue, green, and yellow visible fluorescence observed by the naked eyes. The color of colloidal ZnSiQD suspension became darker when the $\mathrm{NH}_{4} \mathrm{OH}$ content was increased from $15 \mu \mathrm{L}$ to $20 \mu \mathrm{L}$ to $25 \mu \mathrm{L}$, where each sample showed a sharp (intense) emission peak under $365 \mathrm{~nm}$ excitation. This indicated the vital role of $\mathrm{NH}_{4} \mathrm{OH}$ in altering the morphology of the ZnSiQDs. Table 1 shows the sensitiveness of the emission peak wavelength and the corresponding spectral full width at half the maximum of the $\mathrm{ZnSiQDs}$ on the variation of the $\mathrm{NH}_{4} \mathrm{OH}$ content. This observed difference in the emission spectral properties of the three samples was attributed to the schism of the particles in the suspension due to activation via $\mathrm{NH}_{4} \mathrm{OH}$. With the increase in $\mathrm{NH}_{4} \mathrm{OH}$ contents, the particle size was increased, generating short bonds between the tiny $\mathrm{ZnSiQDs}$ and enhancing the nucleation and growth rates. The strong fluorescence emission from $\mathrm{ZnSiQDs}$ containing $15 \mu \mathrm{L}$ of $\mathrm{NH}_{4} \mathrm{OH}$ originated from the pure SiQDs, where the amount of $\mathrm{NH}_{4} \mathrm{OH}$ was insufficient for the SiQDs surface passivation by the ZnO shell [41]. Conversely, for the $\mathrm{ZnSiQDs}$ containing 20 and $25 \mu \mathrm{L}$ of $\mathrm{NH}_{4} \mathrm{OH}$, the emission peaks were related to defects in the $\mathrm{ZnO}$ crystal (oxygen vacancy) that was generated as the shell structure on the SiQDs' surface due to the abundance of $\mathrm{NH}_{4} \mathrm{OH}$ and passivation of the SiQDs' core. Besides, the variation in the emission peak position of the ZnSiQDs with $\mathrm{NH}_{4} \mathrm{OH}$ contents can be attributed to an alteration in the optical bandgap energy because of the quantum-size effect. The narrow emission spectrum implied the same (uniform) QD size in all samples [44], wherein the presence of $\mathrm{NH}_{4} \mathrm{OH}$ enabled the re-growth of 
the $\mathrm{ZnSiQDs}$ to the same size. To confirm this claim, the colloidal $\mathrm{ZnSiQD}$ suspension was further tested at different excitation wavelengths $(365,390$, and $425 \mathrm{~nm})$ as shown in Figure $12 b$.

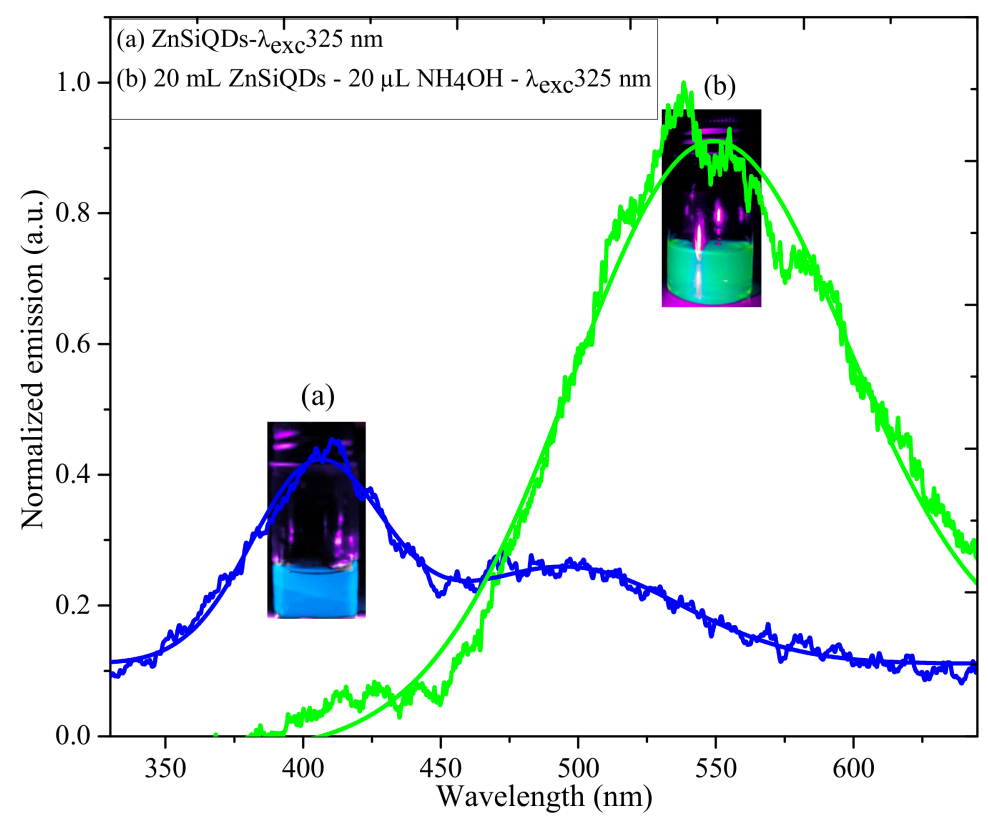

Figure 10. PL spectra (excited at $325 \mathrm{~nm}$ ) of the colloidal ZnSiQD suspension in acetone synthesized (a) without and (b) with $\mathrm{NH}_{4} \mathrm{OH}(20 \mu \mathrm{L})$. The bottles in the inset show the corresponding blue and green visible fluorescence observed by the naked eyes.

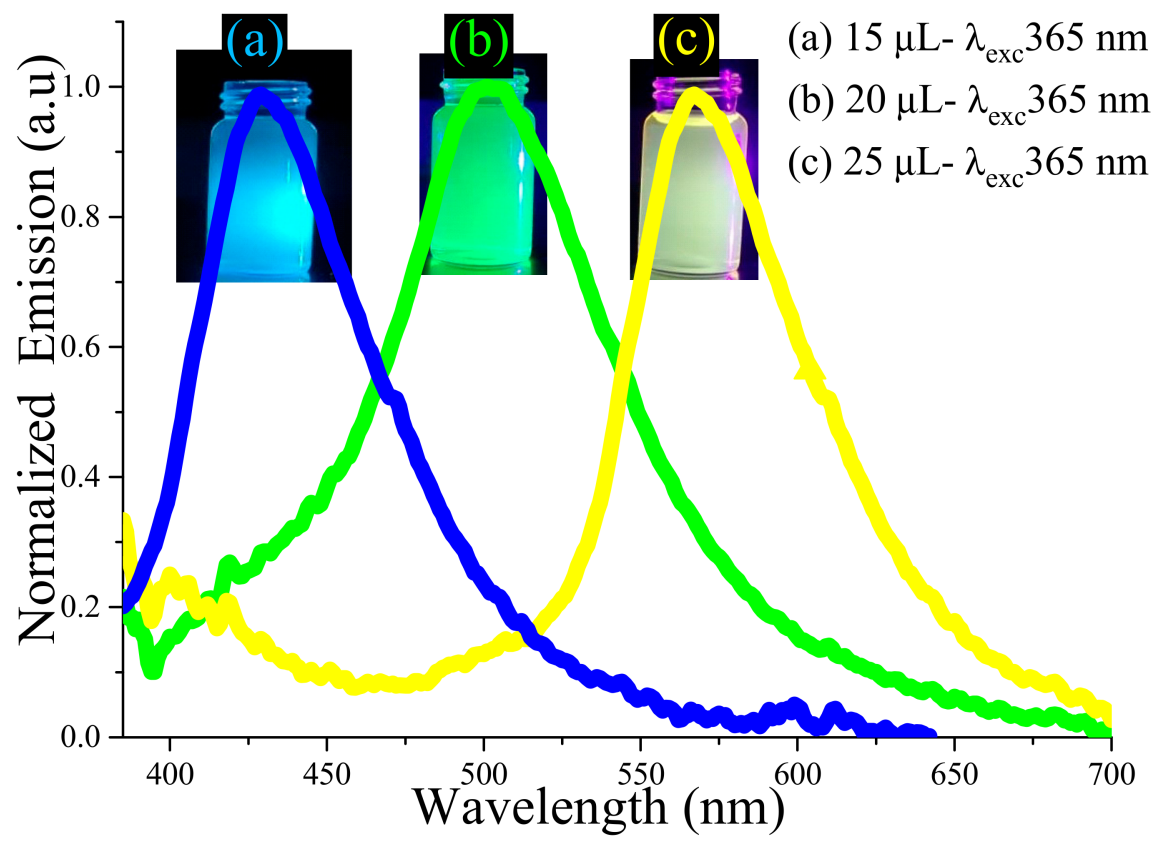

Figure 11. PL spectra (excited at $365 \mathrm{~nm}$ ) of the colloidal $\mathrm{ZnSiQDs}$ synthesized with $\mathrm{NH}_{4} \mathrm{OH}$ of (a) $15 \mu \mathrm{L}$, (b) $20 \mu \mathrm{L}$, and (c) $25 \mu \mathrm{L}$. 
Table 1. Dependence of the emission peak wavelength ( $\lambda$ peak) and the corresponding spectral full width at half the maximum $\mathrm{ZnSiQDs}$ on the variation of the $\mathrm{NH}_{4} \mathrm{OH}$ content.

\begin{tabular}{ccc}
\hline $\mathbf{N H}_{\mathbf{4}} \mathbf{O H}(\mu \mathrm{L})$ & $\lambda_{\text {peak }}(\mathbf{n m})$ & FWHM (nm) \\
\hline 15 & 428 & 68 \\
\hline 20 & 501 & 87 \\
\hline 25 & 567 & 80 \\
\hline
\end{tabular}
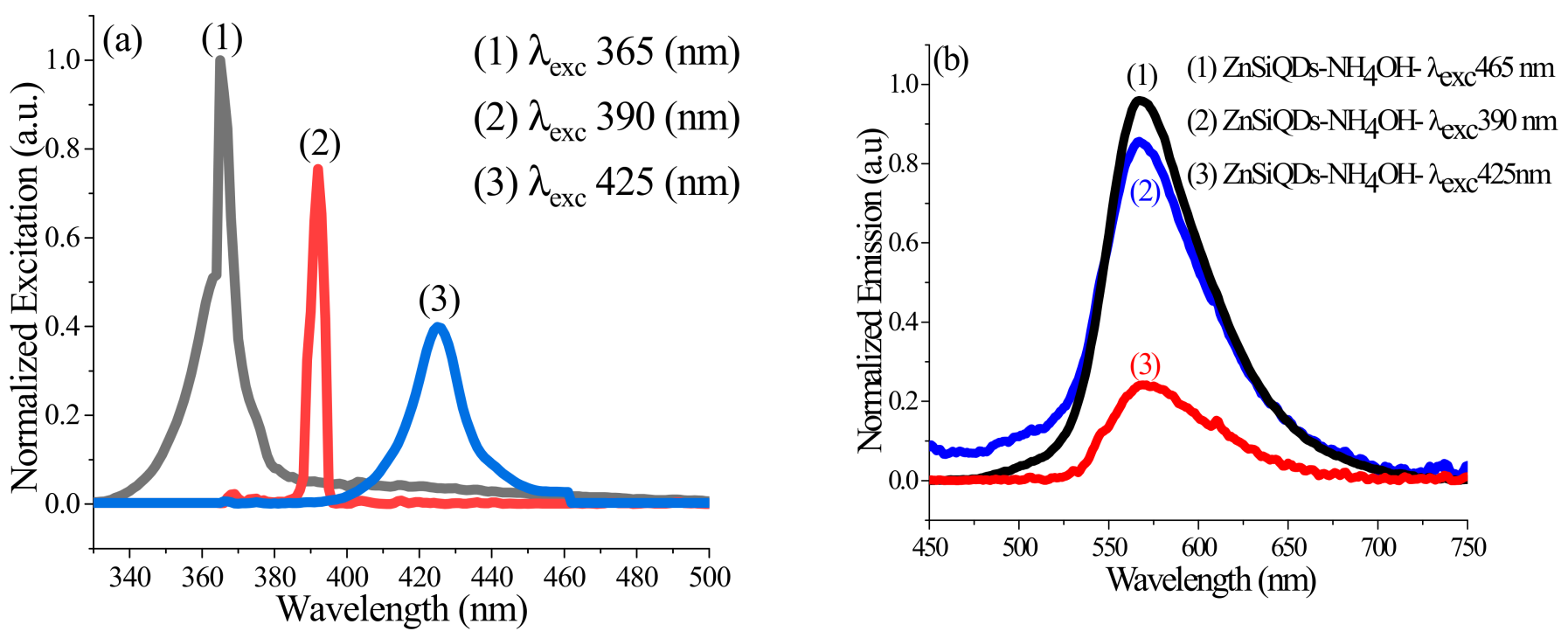

Figure 12. (a) Excitation spectra of source at excitation peak of (1) $365 \mathrm{~nm}$, (2) $390 \mathrm{~nm}$, and (3) $425 \mathrm{~nm}$. (b) PL spectra of the colloidal ZnSiQD suspension in acetone containing $25 \mu \mathrm{L}$ of $\mathrm{NH}_{4} \mathrm{OH}$ excited at the wavelengths of (1) $365 \mathrm{~nm}$, (2) $390 \mathrm{~nm}$, and (3) $425 \mathrm{~nm}$.

Figure 12a shows excitation spectra of the source at an excitation peak of (1) $365 \mathrm{~nm}$, (2) $390 \mathrm{~nm}$, and (3) $425 \mathrm{~nm}$, while Figure 12b illustrates the emission spectra of the colloidal $\mathrm{ZnSiQD}$ suspension with $25 \mu \mathrm{L}$ of $\mathrm{NH}_{4} \mathrm{OH}$ added and excitation at various wavelengths. Table 2 shows the sensitivity of the emission peak wavelength of the corresponding spectral full width at half-maximum on the excitation wavelength variation. The emission peak position is independent of the excitation wavelength changes, indicating the existence of uniform-sized QDs in the suspension [18] or potentially a surface-state-related emission rather than the emission from the ZnSiQDs' core. The emission intensity of the ZnSiQDs excited at $365 \mathrm{~nm}$ and $390 \mathrm{~nm}$ was almost the same, indicating their similar bandgap energy. However, the emission intensity of the $\mathrm{ZnSiQDs}$ excited at $425 \mathrm{~nm}$ was reduced five times, implying that the bandgap energy of the QDs was greater than excitation energy [45]. Figure 12a shows that the lowest intensity of the excitation source was at a wavelength of $425 \mathrm{~nm}$, which is less than $40 \%$ of the excitation wavelength at $365 \mathrm{~nm}$; therefore, it contains a small number of photons compared to other excitation sources. Because of this, the emission density decreases by a massive amount because the excitation source includes a few photons.

Figure 13 illustrates the UV-Vis absorbance of the colloidal ZnSiQD suspension in acetone synthesized with different amounts of $\mathrm{NH}_{4} \mathrm{OH}(15,20$, and $25 \mu \mathrm{L})$. The inset shows the $\mathrm{NH}_{4} \mathrm{OH}$ content-dependent variation in the optical bandgap energy of the $\mathrm{ZnSiQDs}$. The value of bandgap energy was decreased from 3.6 to $2.2 \mathrm{eV}$ with the increase in $\mathrm{NH}_{4} \mathrm{OH}$ contents from 15 to $25 \mu \mathrm{L}$, respectively. This drop in the bandgap energy value can be attributed to the generation of many $\mathrm{OH}^{-}$and $\mathrm{NH}^{4+}$ from the higher volume of $\mathrm{NH}_{4} \mathrm{OH}$, allowing for the growth of large ZnSiQDs [46]. 
Table 2. Dependence of the emission peak wavelength and the corresponding spectral full width at half-maximum $\mathrm{ZnSiQDs}$ on the excitation wavelength changes.

\begin{tabular}{ccc}
\hline$\lambda_{\text {exc }}(\mathbf{n m})$ & $\lambda_{\text {peak }}(\mathbf{n m})$ & FWHM (nm) \\
\hline 425 & 567 & 70 \\
\hline 390 & 567 & 57 \\
\hline 365 & 567 & 62 \\
\hline
\end{tabular}

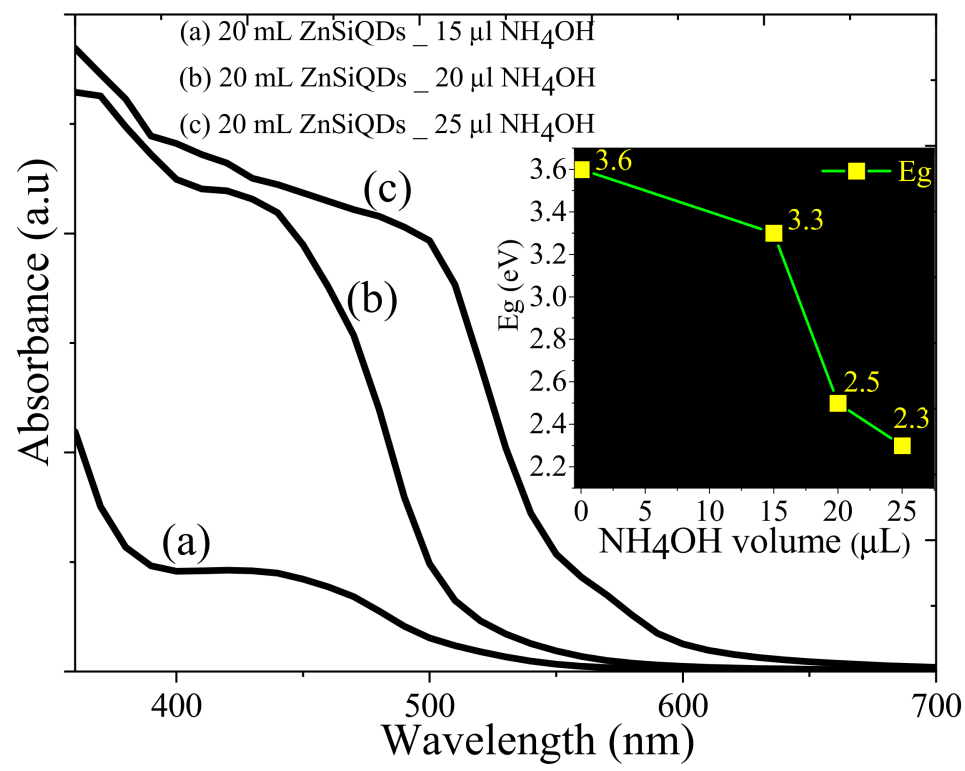

Figure 13. UV-vis absorbance of the colloidal ZnSiQD suspension in acetone synthesized with $\mathrm{NH}_{4} \mathrm{OH}$ of (a) $15 \mu \mathrm{L}$ (b), $20 \mu \mathrm{L}$, and (c) $25 \mu \mathrm{L}$.

\subsection{Mechanism of ZnSiQDs Formation with $\mathrm{NH}_{4} \mathrm{OH}$}

Figure 14 presents the mechanism of $\mathrm{NH}_{4} \mathrm{OH}$ influence on the $\mathrm{ZnO}$ shell where the additive $\mathrm{NH}_{4} \mathrm{OH}$ is adsorbed into the $\mathrm{ZnSiQDs}$. When $\mathrm{NH}_{4} \mathrm{OH}$ was added to the colloidal $\mathrm{ZnSiQDs}$ in acetone, it was dissociated into $\mathrm{NH}_{4}{ }^{+}$and $\mathrm{OH}^{-} .\left(\mathrm{Zn}\left(\mathrm{NH}_{3}\right)_{4}\right)^{+2}$ and $\mathrm{Zn}(\mathrm{OH})_{2}$ or $\left(\mathrm{Zn}(\mathrm{OH})_{4}\right)^{+2}$ ) were produced due to the reaction of $\mathrm{Zn}^{+2}$ with $\mathrm{NH}_{4}{ }^{+}$and $\mathrm{OH}^{-}$, respectively. The chemical reactions can be inferred through the following pathways [47]:

$$
\begin{aligned}
\text { Path I: } & \mathrm{Zn}^{+2}+2 \mathrm{OH}^{-} \rightarrow \mathrm{Zn}(\mathrm{OH})_{2} \\
\text { Path II: } & \mathrm{Zn}^{+2}+4 \mathrm{OH}^{-} \rightarrow \mathrm{Zn}(\mathrm{OH})_{4}{ }^{-2} \\
\text { Path III: } & \mathrm{Zn}^{+2}+4 \mathrm{NH}_{4}^{+} \rightarrow \mathrm{Zn}\left(\mathrm{NH}_{3}\right)_{4}{ }^{+2}
\end{aligned}
$$

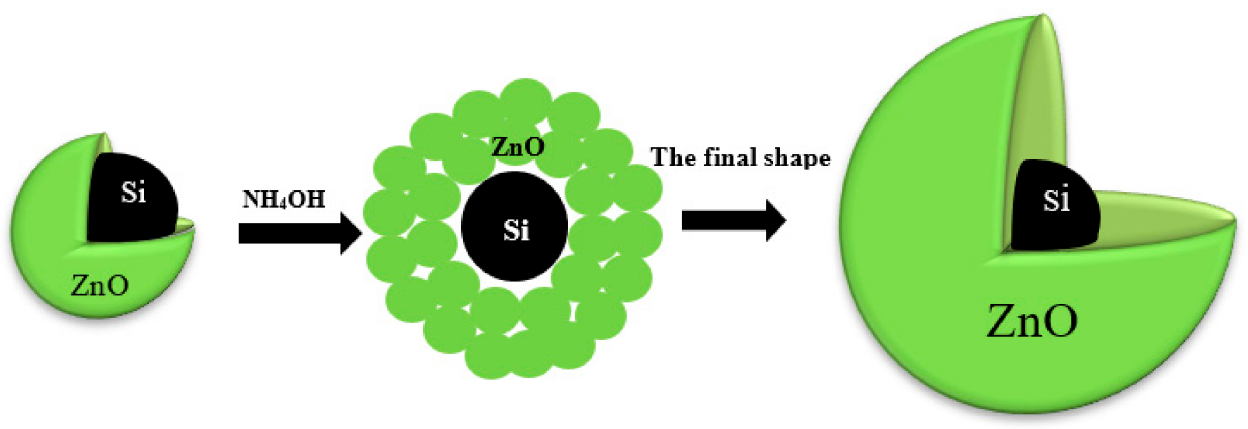

Figure 14. The schematic diagram for the mechanism of $\mathrm{NH}_{4} \mathrm{OH}$ influence on the $\mathrm{ZnO}$ shell. 
The unstable nature of $\mathrm{Zn}(\mathrm{OH})_{4}{ }^{-2}, \mathrm{Zn}(\mathrm{OH})_{2}$, and $\mathrm{Zn}\left(\mathrm{NH}_{3}\right)_{4}{ }^{+2}$ enabled $\mathrm{Zn}\left(\mathrm{NH}_{3}\right)_{4}{ }^{+2}$ to react with $\mathrm{OH}^{-}$via the chemical pathway [47]:

$$
\text { Path IV: } \mathrm{Zn}\left(\mathrm{NH}_{3}\right)_{4}{ }^{+2}+2 \mathrm{OH}^{-} \rightarrow \mathrm{ZnO}+4 \mathrm{NH}_{3}+\mathrm{H}_{2} \mathrm{O}
$$

The produced $\mathrm{Zn}(\mathrm{OH})_{4}{ }^{-2}$ congregates in the solvent, and $\mathrm{ZnO}$ served as the core of new aggregates while the surface generally contained $\mathrm{Zn}^{+2}$ and $\mathrm{OH}^{-}$. The size of the aggregates was increased due to the association of more $\mathrm{Zn}^{+2}$ and $\mathrm{OH}^{-}$via the following. The chemical paths 5 and 6 summarize the last proposal [48]

$$
\begin{aligned}
& \text { Path V: } \quad \mathrm{Zn}(\mathrm{OH})_{4}{ }^{+2} \rightarrow \mathrm{ZnO}+\mathrm{H}_{2} \mathrm{O}+2 \mathrm{OH}^{-} \\
& \text {Path VI: } \quad \mathrm{Zn}(\mathrm{OH})_{2}+2 \mathrm{OH}^{-} \rightarrow \mathrm{Zn}(\mathrm{OH})_{4}{ }^{+2}
\end{aligned}
$$

With the increase in $\mathrm{NH}_{4} \mathrm{OH}$ contents, the number of $\mathrm{NH}_{4}{ }^{+}$and $\mathrm{OH}^{-}$was increased, thereby increasing the number of ion aggregates to produce the $\mathrm{ZnO}$ shell with $\mathrm{Zn}^{+2}$ and $\mathrm{OH}^{-}$as the surface bonds. Consequently, the $\mathrm{ZnO}$ nanocrystalline shell grew along the $z$-axis due to its high-energy polar planar orientation, thereby producing nanorods [47]. This argument was supported by both EFTEM and FESEM images which showed spherical $\mathrm{ZnSiQDs}$, indicating the growth of a $\mathrm{ZnO}$ nanocrystalline shell in different directions due to the presence of $\mathrm{NH}_{4} \mathrm{OH}$ as a complexing agent to shift $\mathrm{ZnO}$ preferential growth orientation.

\section{Conclusions}

A new record for the improvement of room-temperature brightness (blue, green, and orange-yellow) of colloidal $\mathrm{ZnSiQD}$ suspension in acetone is reported for the first time. Such colloidal ZnSiQDs were synthesized using a combination of top-down and bottom-up approaches. The synergy between these two methods enabled the production of these QDs with uniform sizes and shapes together with their re-growth. The inclusion of various amounts of $\mathrm{NH}_{4} \mathrm{OH}$ (15 to $25 \mu \mathrm{L}$ ) into the colloidal $\mathrm{ZnSiQD}$ suspension was shown to play a significant role, altering the overall morphology and optical properties of the $\mathrm{ZnSiQDs}$. The formation of the $\mathrm{ZnO}$ shell around the SiQDs core via surface passivation due to the activation of $\mathrm{NH}_{4} \mathrm{OH}$ was responsible for improving the optical traits of the colloidal $\mathrm{ZnSiQDs}$, especially the room-temperature visible luminescence. Using a mechanism with different chemical reaction pathways, it was argued that $\mathrm{NH}_{4} \mathrm{OH}$ served to grow the $\mathrm{ZnSiQDs}$ by an assembly of tiny particles to produce larger particles or re-grow the $\mathrm{ZnO}$ shell surrounding the SiQDs. The optical attributes of the $\mathrm{ZnSiQDs}$ were remarkably improved. The emission-peak wavelengths were independent of the excitation wavelengths and strongly dependent on the $\mathrm{NH}_{4} \mathrm{OH}$ contents, indicating the nucleation of QDs with a uniform size distribution. The colloidal $\mathrm{ZnSiQDs}$ exhibited a broad range of visible emissions in the blue, green, and orange-yellow region, indicating their effectiveness for the tandem solar cell and liquid laser applications. It is worth evaluating the effect of time on the growth process, which may elucidate more benefits of $\mathrm{NH}_{4} \mathrm{OH}$-activated $\mathrm{ZnSiQD}$ development for functional applications. Future tasks will be focused on utilizing these QDs in rainbow solar cells.

Author Contributions: Conceptualization, N.M.A. and M.R.; methodology, N.M.A., M.R.; software, M.S.A. and N.M.A.; validation, H.A., M.K.M.A., O.A. and K.H.I.; formal analysis, M.S.A.; investigation, M.S.A.; resources, N.M.A. and H.A.; data curation, M.S.A., M.K.M.A., O.A., K.H.I.; writing—original draft preparation, M.S.A., N.M.A.; writing—review and editing, H.A. M.K.M.A., K.H.I., O.A.; visualization, N.M.A. and M.R.; supervision, N.M.A. and M.R.; project administration, N.M.A., O.A., K.H.I.; funding acquisition, H.A. and O.A. All authors have read and agreed to the published version of the manuscript.

Funding: This research was funded by Deanship of Scientific Research at Imam Mohammad Ibn Saud Islamic University through Research Group No. RG-21-09-52. 
Acknowledgments: The authors extend their appreciation to the Deanship of Scientific Research at Imam Mohammad Ibn Saud Islamic University for funding this work. The authors gratefully acknowledge Ahmed Alsadig (University of Trieste) for his kind assistance throughout this work.

Conflicts of Interest: The authors declare no conflict of interest.

\section{References}

1. Rizzi, F.; Castaldo, R.; Latronico, T.; Lasala, P.; Gentile, G.; Lavorgna, M.; Striccoli, M.; Agostiano, A.; Comparelli, R.; Depalo, N.; et al. High Surface Area Mesoporous Silica Nanoparticles with Tunable Size in the Sub-Micrometer Regime: Insights on the Size and Porosity Control Mechanisms. Molecules 2021, 26, 4247. [CrossRef] [PubMed]

2. Mangolini, L. Synthesis, properties, and applications of silicon nanocrystals. J. Vac. Sci. Technol. B 2013, 31, 020801. [CrossRef]

3. Ghosh, B.; Shirahata, N. Colloidal silicon quantum dots: Synthesis and luminescence tuning from the near-UV to the near-IR range. Sci. Technol. Adv. Mater. 2014, 15, 014207. [CrossRef] [PubMed]

4. Terada, S.; Xin, Y.; Saitow, K.-I. Cost-Effective Synthesis of Silicon Quantum Dots. Chem. Mater. 2020, 32, 8382-8392. [CrossRef]

5. Kang, Z.; Tsang, A.C.H.; Zhang, Z.; Zhang, M.; Wong, N.-B.; Zapien, J.A.; Shan, Y.; Lee, S.-T. A Polyoxometalate-Assisted Electrochemical Method for Silicon Nanostructures Preparation: From Quantum Dots to Nanowires. J. Am. Chem. Soc. 2007, 129, 5326-5327. [CrossRef]

6. Heinrich, J.L.; Curtis, C.L.; Credo, G.M.; Sailor, M.J.; Kavanagh, K.L. Luminescent Colloidal Silicon Suspensions from Porous Silicon. Science 1992, 255, 66-68. [CrossRef]

7. Roy, D.; Mukhuty, A.; Fouzder, C.; Bar, N.; Chowdhury, S.; Kundu, R.; Chowdhury, P. Multi-emissive biocompatible silicon quantum dots: Synthesis, characterization, intracellular imaging and improvement of two fold drug efficacy. Dye. Pigment. 2020, 186, 109004. [CrossRef]

8. Sychugov, I.; Pevere, F.; Luo, J.-W.; Zunger, A.; Linnros, J. Single-dot absorption spectroscopy and theory of silicon nanocrystals. Phys. Rev. B 2016, 93, 161413. [CrossRef]

9. Almomani, M.S.; Ahmed, N.M.; Rashid, M.; Almessiere, M.; Altowyan, A.S. Broadband visible emission from photoelectrochemical etched porous silicon quantum dots containing zinc. Mater. Chem. Phys. 2020, 258, 123935. [CrossRef]

10. Yamada, H.; Saitoh, N.; Ghosh, B.; Masuda, Y.; Yoshizawa, N.; Shirahata, N.E. Improved Brightness and Color Tunability of Solution-Processed Silicon Quantum Dot Light-Emitting Diodes. J. Phys. Chem. C 2020, 124, 23333-23342. [CrossRef]

11. Norazmi, F.S.; Chaudhary, K.T.; Mazalan, E.; Hader, Z.; Ali, J. Effect of various amount of ammonium hydroxide on morphology of silica nanoparticles grown by sol-gel. Malays. J. Fundam. Appl. Sci. 2018, 14, 482-484. [CrossRef]

12. Sasirekha, N.; Rajesh, B.; Chen, Y.-W. Synthesis of $\mathrm{TiO}_{2}$ sol in a neutral solution using $\mathrm{TiCl}_{4}$ as a precursor and $\mathrm{H}_{2} \mathrm{O}_{2}$ as an oxidizing agent. Thin Solid Films 2009, 518, 43-48. [CrossRef]

13. Harris, M.T.; Brunson, R.R.; Byers, C.H. The base-catalyzed hydrolysis and condensation reactions of dilute and concentrated TEOS solutions. J. Non-Cryst. Solids 1990, 121, 397-403. [CrossRef]

14. Peternele, W.S.; Fuentes, V.M.; Fascineli, M.L.; Da Silva, J.R.; Silva, R.C.; Lucci, C.; De Azevedo, R.B. Experimental Investigation of the Coprecipitation Method: An Approach to Obtain Magnetite and Maghemite Nanoparticles with Improved Properties. J. Nanomater. 2014, 2014, 94. [CrossRef]

15. Zeng, H.; Zhai, L.; Qiao, T.; Yu, Y.; Zhang, J.; Li, D. Efficient removal of As(V) from aqueous media by magnetic nanoparticles prepared with Iron-containing water treatment residuals. Sci. Rep. 2020, 10, 9335. [CrossRef]

16. Almomani, M.S.; Ahmed, N.M.; Rashid, M.; Almessiere, M.A.; Altowyan, A.S. White, blue and green emission from Si QDs derived from zinc incorporated porous silicon. J. Lumin. 2020, 232, 117845. [CrossRef]

17. Green, D.; Lin, J.; Lam, Y.-F.; Hu, M.; Schaefer, D.W.; Harris, M. Size, volume fraction, and nucleation of Stober silica nanoparticles. J. Colloid Interface Sci. 2003, 266, 346-358. [CrossRef]

18. Dalvand, R.; Mahmud, S.; Alimanesh, M.; Vakili, A.H. Optical and structural properties of well-aligned ZnO nanoneedle arrays grown on porous silicon substrates by electric field-assisted aqueous solution method. Ceram. Int. 2017, 43, 1488-1494. [CrossRef]

19. Graniel, O.; Iatsunskyi, I.; Coy, E.; Humbert, C.; Barbillon, G.; Michel, T.; Maurin, D.; Balme, S.; Miele, P.; Bechelany, M. AuCovered hollow urchin-Like ZnO nanostructures for surface-Enhanced Raman scattering sensing. J. Mater. Chem. C 2019, 7, 15066-15073. [CrossRef]

20. Shirahata, N. Colloidal Si nanocrystals: A controlled organic-inorganic interface and its implications of color-tuning and chemical design toward sophisticated architectures. Phys. Chem. Chem. Phys. 2011, 13, 7284-7294. [CrossRef]

21. Salcedo, W.J.; Braga, M.S.; Jaimes, R.F. Huge enhancement of photoluminescence emission from porous silicon film doped with Cr(III) ions. J. Lumin. 2018, 199, 109-111. [CrossRef]

22. Koch, F.; Petrova-Koch, V.; Muschik, T. The luminescence of porous Si: The case for the surface state mechanism. J. Lumin. 1993, 57, 271-281. [CrossRef]

23. Sarswat, P.K.; Free, M.L. Light emitting diodes based on carbon dots derived from food, beverage, and combustion wastes. Phys. Chem. Chem. Phys. 2015, 17, 27642-27652. [CrossRef]

24. Brachmann, E.; Seifert, M.; Oswald, S.; Menzel, S.B.; Gemming, T. Evaluation of Surface Cleaning Procedures for CTGS Substrates for SAW Technology with XPS. Materials 2017, 10, 1373. [CrossRef]

25. Joo, B.S.; Gu, M.; Han, J.; Jung, N.; Kim, S.; Park, D.-W.; Han, M. Decay time dynamics of red and blue luminescence of surface-functionalized silicon quantum dots. J. Lumin. 2021, 236, 118121. [CrossRef] 
26. Aslanov, L.A.; Zaytsev, V.B.; Zakharov, V.N.; Kudryavtsev, I.K.; Senyavin, V.M.; Lagov, P.B.; Pavlov, Y.S. Nanosilicon stabilized with ligands: Effect of high-energy electron beam on luminescent properties. Surf. Interface Anal. 2020, 52, 957-961. [CrossRef]

27. Hussein, M.J.; Yunus, W.M.M.; Kamari, H.M.; Zakaria, A.; Oleiw, H.F. Effect of current density and etching time on photoluminescence and energy band gap of p-type porous silicon. Opt. Quantum Electron. 2016, 48, 194. [CrossRef]

28. Ramesh, M.; Nagaraja, H. Effect of current density on morphological, structural and optical properties of porous silicon. Mater. Today Chem. 2017, 3, 10-14. [CrossRef]

29. Ingham, B.; Toney, M.F. X-ray diffraction for characterizing metallic films. In Metallic Films for Electronic, Optical and Magnetic Applications: Structure, Processing and Properties; Elsevier: Amsterdam, The Netherlands, 2014; pp. 3-38.

30. Barbagiovanni, E.; Lockwood, D.J.; Simpson, P.J.; Goncharova, L.V. Quantum confinement in Si and Ge nanostructures: Theory and experiment. Appl. Phys. Rev. 2014, 1, 011302. [CrossRef]

31. Babu, K.S.; Reddy, A.R.; Sujatha, C.; Reddy, K.V.; Mallika, A.N. Synthesis and optical characterization of porous ZnO. J. Adv. Ceram. 2013, 2, 260-265. [CrossRef]

32. Xiong, H.-M.; Shchukin, D.G.; Möhwald, H.; Xu, Y.; Xia, Y.-Y. Sonochemical Synthesis of Highly Luminescent Zinc Oxide Nanoparticles Doped with Magnesium(II). Angew. Chem. Int. Ed. 2009, 48, 2727-2731. [CrossRef] [PubMed]

33. Nandi, S.K.; Chakraborty, S.; Bera, M.K.; Maiti, C.K. Structural and optical properties of ZnO films grown on silicon and their applications in MOS devices in conjunction with $\mathrm{ZrO} 2$ as a gate dielectric. Bull. Mater. Sci. 2007, 30, 247-254. [CrossRef]

34. Suwatthanarak, T.; Than-Ardna, B.; Danwanichakul, D.; Danwanichakul, P. Synthesis of silver nanoparticles in skim natural rubber latex at room temperature. Mater. Lett. 2016, 168, 31-35. [CrossRef]

35. Rashid, M.; Ahmed, N.M.; Noor, N.A.M.; Pakhuruddin, M.Z. Silicon quantum dot/black silicon hybrid nanostructure for broadband reflection reduction. Mater. Sci. Semicond. Process. 2020, 115, 105113. [CrossRef]

36. Devine, R. Macroscopic and microscopic effects of radiation in amorphous $\mathrm{SiO}_{2}$. Nucl. Instrum. Methods Phys. Res. Sect. B Beam Interact. Mater. At. 1994, 91, 378-390. [CrossRef]

37. Wagner, C.D.; Passoja, D.E.; Hillery, H.F.; Kinisky, T.G.; Six, H.A.; Jansen, W.T.; Taylor, J.A. Auger and photoelectron line energy relationships in aluminum-oxygen and silicon-oxygen compounds. J. Vac. Sci. Technol. 1982, 21, 933-944. [CrossRef]

38. Dake, L.S.; Baer, D.R.; Zachara, J.M. Auger parameter measurements of zinc compounds relevant to zinc transport in the environment. Surf. Interface Anal. 1989, 14, 71-75. [CrossRef]

39. Wu, J.; Dai, J.; Shao, Y.; Sun, Y. One-step synthesis of fluorescent silicon quantum dots (Si-QDs) and their application for cell imaging. RSC Adv. 2015, 5, 83581-83587. [CrossRef]

40. Fujii, M.; Minami, A.; Sugimoto, H. Precise size separation of water-soluble red-to-near-infrared-luminescent silicon quantum dots by gel electrophoresis. Nanoscale 2020, 12, 9266-9271. [CrossRef]

41. Proot, J.P.; Delerue, C.; Allan, G. Electronic structure and optical properties of silicon crystallites: Application to porous silicon. Appl. Phys. Lett. 1992, 61, 1948-1950. [CrossRef]

42. Cheng, X.; Lowe, S.B.; Reece, P.J.; Gooding, J.J. Colloidal silicon quantum dots: From preparation to the modification of self-assembled monolayers (SAMs) for bio-applications. Chem. Soc. Rev. 2014, 43, 2680-2700. [CrossRef]

43. Peng, X.; Manna, L.; Yang, W.; Wickham, J.; Scher, E.; Kadavanich, A.; Alivisatos, A.P. Shape control of CdSe nanocrystals. Nature 2000, 404, 59-61. [CrossRef] [PubMed]

44. Taheri, M.; Mansour, N. Silicon Nanoparticles Produced by Two-Step Nanosecond Pulsed Laser Ablation in Ethanol for Enhanced Blue Emission Properties. Silicon 2019, 12, 789-797. [CrossRef]

45. Jacobsson, T.J.; Viarbitskaya, S.; Mukhtar, E.; Edvinsson, T. A size dependent discontinuous decay rate for the exciton emission in ZnO quantum dots. Phys. Chem. Chem. Phys. 2014, 16, 13849-13857. [CrossRef]

46. Singh, M.; Goyal, M.; Devlal, K. Size and shape effects on the band gap of semiconductor compound nanomaterials. J. Taibah Univ. Sci. 2018, 12, 470-475. [CrossRef]

47. Thein, M.T.; Pung, S.-Y.; Aziz, A.; Itoh, M. The role of ammonia hydroxide in the formation of ZnO hexagonal nanodisks using sol-gel technique and their photocatalytic study. J. Exp. Nanosci. 2014, 10, 1068-1081. [CrossRef]

48. van Dijken, A.; Meulenkamp, E.; Vanmaekelbergh, D.; Meijerink, A. The luminescence of nanocrystalline ZnO particles: The mechanism of the ultraviolet and visible emission. J. Lumin. 2000, 87-89, 454-456. [CrossRef] 